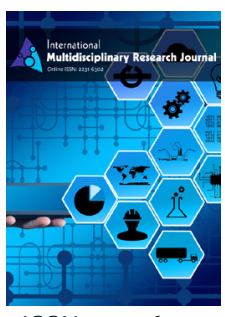

ISSN: 2231-6302

\title{
The impacts of electric vehicles and heat pumps load profiles on low voltage distribution networks in Great Britain by 2050
}

\author{
Rilwan O. Oliyide ${ }^{a, b *}$, Liana M. Cipcigan ${ }^{a}$ \\ anstitute of Energy, School of Engineering, Cardiff University, Cardiff, United Kingdom, 'Department of Electrical/ \\ Electronic Engineering, Moshood Abiola Polytechnic, Abeokuta, Ogun State, Nigeria
}

\begin{abstract}
The impacts of uptake and electricity load profiles of Electric Vehicles (EVs) and Heat Pumps (HPs) on the low voltage (LV) distribution networks were analyzed. The United Kingdom (UK) has a legally mandated policy concerning reduction of greenhouse gasses (GHGs) emissions. Therefore, the integration of low carbon technologies (LCTs) especially EVs and HPs at the LV networks is expected to increase in the drive to reducing the GHGs emissions. Future uptake scenarios, adapted from the National Grid studies, of EVs and HPs were developed for a real and typical urban LV distribution network in Great Britain (GB). Gridlab-D, an agent-based power system simulation software, was used to model the LV distribution network. The model was run for four different scenarios considering seasonal load profiles and projected EVs and HPs uptakes for each of the year 2020, 2030, 2040 and 2050 respectively. The results were analyzed in terms of transformer loading, voltage profiles of the feeders, and the ampacity loading of the cables for the different scenarios of the years.
\end{abstract}

*Corresponding Author:

Rilwan O. Oliyide

oliyide.rilwan@mapoly.edu.ng

KEYWORDS: Electric Vehicles, Heat Pumps, Low voltage network, GridLAB-D, GHG emissions, Transformer loading

\section{INTRODUCTION}

Policies and regulations are adopted at the United Nations to reduce the greenhouse gasses (GHGs) emissions and the effect of the climate change (UNFCCC, 2015). The United Kingdom (UK) has a policy target of $80 \%$ reduction of GHGs emissions with respect to the 1990 level by the year 2050 (CCC, 2015). The realization of the target will involve a transition from fossil fuel based to low carbon-based electricity generation and consumption.

The transportation sector contributed 26\%, the largest by a sector, of GHG emissions in the UK in the year 2016 (DBEIS, 2018). The road transport, especially passenger cars, is the major contributor in this sector. Internal Combustion Engine (ICE) cars, as at the end of 2016, made up about $99 \%$ of all cars licensed by propulsion/fuel type in the UK (DfT, 2017). Also, in the year 2016, the residential sector contributed 14\% of the total GHG emissions in the UK (DBEIS, 2018). The GHG emissions from the residential sector are dominated by natural gas combustion for space heating (DBEIS, 2018). In Great Britain (GB) alone, $84.2 \%$ of households use gas-fired boilers for heating (Ofgem, 2015a). To reduce emissions in the transport sector, EVs are expected to play a dominant role. The UK Government's ambition is that nearly all cars and vans on the roads are zero emission by 2040 (Parliament of UK, 2018). Government says as this number grows EVs will become a "resource for a smart electricity" bringing benefits for drivers and creating a more flexible and efficient energy system (Parliament of UK, 2018).

Therefore, there is considerable potential for cutting down on GHGs emissions with increasing uptake of $\mathrm{EV}$ s for road transportation, HPs for residential heating, and increasing integration of renewable energy sources (RESs) in the electricity generation mix. To this end, the UK Government initiated incentive schemes such as 'Plug-in Car Grant' to encourage uptake of EVs (OLEV, 2018), 'Renewable Heat Incentive' to encourage the switching from fossil fuel heating to renewable heating (DBEIS, 2016) and 'Renewable Obligation', which places a mandatory obligation on the UK's electricity suppliers to source a particular proportion of their electricity from renewable sources (Ofgem, 2018).

Widespread uptake of EVs and HPs will introduce new load patterns, and may lead to much higher peak demand. The 
higher peak demand may impact local LV distribution networks, particularly at clustered locations (Hilshey et al., 2013). The way in which conventional electricity networks have operated in the past is unlikely to manage these new challenges without much higher system costs and perhaps reduction in the overall system reliability (Karki et al., 2014; Farzin et al., 2016).

On this backdrop, the level of awareness, interest and activities related to the studies of impacts of EVs and HPs on the electricity system continue to grow. Many works considered the separate impacts of EVs and HPs on the LV distribution network (Akmal et al., 2014; Leou et al., 2014; Navarro-Espinosa \& Mancarella, 2014; Neaimeh et al., 2015; Awadallah et al., 2016; Protopapadaki \& Saelens, 2017). In (Leou et al., 2014), LV distribution network operation security-risk information, such as over-current and under-voltage due to the uptake of EVs, was obtained from three-phase distribution load flow studies that use stochastic parameters drawn from Monte Carlo. The capability of providing security risk information by deterministic and stochastic analytical approaches was compared and impacts due to controlled and uncontrolled charging were analysed. The work concluded that stochastic approach gives better information, and that controlled charging could mitigate network problems.

In (Navarro-Espinosa \& Mancarella, 2014), probabilistic methodology (Monte Carlo) and OpenDSS power flow software were used to assess the impact of HPs (ASHP and GSHP) on LV distribution network. The results from the studies showed that thermal problems are likely to arise at much earlier uptake levels of HPs than for voltage problems, and moving from upstream components (transformers) to downstream ones (feeders).

The significance of the work described in this paper is that it simultaneously investigated the combined impacts of future uptake of EVs and HPs up to the year 2050 on a typical real urban residential LV distribution network area. GridLAB-D is used for the analysis of the impacts in terms of voltage profile, transformer loading and cable thermal loading. These are evaluated for a range of EVs and HPs integration for 2020, 2030, 2040 and 2050. Section II presents the methodology for modelling and scaling down of national uptake figures of $\mathrm{EVs}$ and HPs for the LV network. Section III presents the LV network modelling and the simulation implementation. The results of the model simulation are presented in section IV, and in section $\mathrm{V}$ conclusions are drawn.

\section{METHODOLOGY}

\section{A. Scenarios Description}

Gridlab-D power system simulation software was used to analyze the impacts of integration of EVs and HPs on a part of real urban LV network. The impact analysis was investigated under four scenarios for each of 2020, 2030, 2040 and 2050 considering projected $\mathrm{EV}$ s and HPs uptake figures and seasonal load profiles. The scenarios are: (1) Steady State Summer Weekday (SSSmrWd), (2) Steady State Winter Weekday
(SSWtrWd), (3) Two Degrees Summer Weekday (TDSmrWd) and (4) Two Degrees Winter Weekday (TDWtrWd).

The Two Degrees (TD) and Steady State (SS) scenarios are adapted from (National Grid, 2017). The scenario name 'Two Degrees' is derived from the Article 2 of the Paris Agreement (UNFCC, 2015) and it indicates the target of holding the increase in the global average temperature to well below $2^{\circ} \mathrm{C}$ above pre-industrial levels. The TD depicts a scenario of prosperous economic growth, increased focus on RESs and LCTs, and strong political drive to achieve the renewable integration and all of UK's 2050 emissions reduction targets. It is a scenario in which technology and investment are focused on innovation in RESs (solar and wind) and low carbon (nuclear) generation. On the other hand, the SS scenario depicts a business-as-usual scenario with less prosperous economic growth, little innovation in RESs and LCTs and limited political drive to encourage the populace to embrace greener LCTs. In SS scenario, technological innovation and investment are business as usual, low risk and short-term value approach, which focus on security of supply at affordable cost.

\section{B. Details of the Case Study LV Network}

In this study, a typical real urban LV distribution network in GB is used as the case study. The area is supplied by a $500-\mathrm{kVA}$, 11/0.415-kV (no load), 50-Hz, Dynl 1, ONAN mineral oil filled, free breathing, ground mounted transformer. The transformer supplies 298 buildings in four feeders. Figure 1 is the simplified diagram of the LV network and Table 1 gives the analysis of the number of buildings per feeder, annual baseline load of the feeders in 2014 and the length of the feeders.

Analysis of the feeders indicates that both Feeders 1 and 2 have feeder density of approximately 8 and 9 buildings per $100 \mathrm{~m}$ length of the feeder respectively. Feeders 3 and 4, on the other hand, both have feeder density of approximately 11 and 13 buildings per $100 \mathrm{~m}$ length of the feeder respectively.

\section{Future Electricity Demand Projections for the LV Network}

In this research work, residential baseline electricity demand is described as the household electricity demand which excludes the electricity demand of EVs and HPs. Projected residential annual baseline electricity demand for 2020, 2030, 2040 and 2050 are estimated from the breakdown analysis of the annual demand presented in National Grid's Future Energy Scenarios (National Grid, 2017). Residential annual electricity demand in GB in 2014, which is the reference year in this work, was 109TWh (DECC, 2015). In 2014, the uptake levels

Table 1: Feeders analysis

\begin{tabular}{cccc}
\hline Feeder & $\begin{array}{c}2014 \text { Annual load } \\
(\mathrm{kWh})\end{array}$ & Length $(\mathrm{m})$ & $\begin{array}{c}\text { Number of Buildings } \\
\text { (Units) }\end{array}$ \\
\hline 1 & $360,782.4$ & 1190 & 95 \\
2 & $202,291.8$ & 555 & 51 \\
3 & $402,697.1$ & 1155 & 120 \\
4 & $108,936.0$ & 250 & 32 \\
& $1,074,707.30$ & & 298 \\
\hline
\end{tabular}




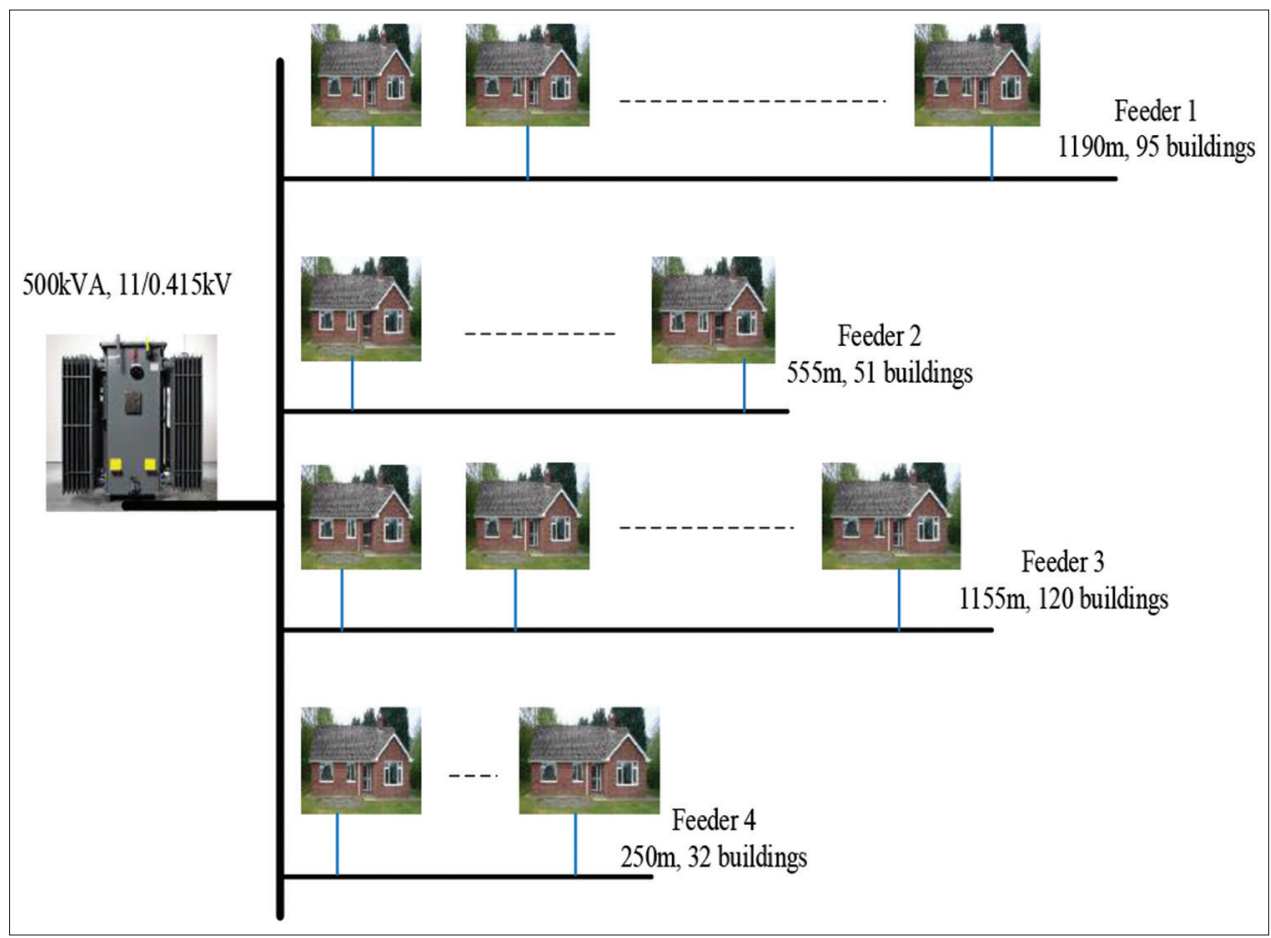

Figure 1: Simplified diagram of the case study LV network

of both EVs and HPs were very small, and their combined electricity demand was not visible in the total residential annual electricity demand presented in (National Grid, 2017) and (DECC, 2015). Therefore, residential annual electricity demand in 2014 is regarded as 'reference baseline' in the context of this work. Residential relative baseline electricity demands for 2020, 2030, 2040 and 2050 with respect to 2014 are calculated. Given the 2014 residential annual electricity demand of the case study LV network, then its projected future annual baseline electricity demand can be obtained by equation (1).

$$
L V_{\text {baseline }_{\text {dmd }(y r)}}=L V_{\text {baseline }_{\text {dmud(2014) }}} \times R e l_{(y r)}
$$

Where:

$L V_{\text {baseline }_{\text {dnd }}(r)}$ is the projected LV network annual baseline electricity demand (MWh) of a particular year.

$L V_{\text {baseline }_{\text {dnd (2014) }}}$ is the baseline electricity demand (MWh) of the case study LV network in 2014.

$\operatorname{Rel}\left(_{y r}\right)$ is the relative baseline demand of a particular year with respect to 2014 and $y r$ is the year identifier index.

Projected annual baseline demand of the LV network for the respective years are converted to half-hourly seasonal (summer weekday and winter weekday) daily profiles based on the normalization of the profiles from (UKERC, n.d.).
Table 2: GB residential annual baseline demand and relative baseline demand

\begin{tabular}{ccc}
\hline Year & $\begin{array}{c}\text { Annual Baseline } \\
\text { Demand (TWh) }\end{array}$ & $\begin{array}{c}\text { Relative Baseline } \\
\text { Demand }\end{array}$ \\
\hline 2014 & 109 & 1.00 \\
2020 & 112 & 1.03 \\
2030 & 113 & 1.04 \\
2040 & 118 & 1.08 \\
2050 & 129 & 1.18 \\
\hline
\end{tabular}

Table 2 gives the summary of the residential annual baseline demands for 2014, projected residential annual baseline demand for 2020, 2030, 2040 and 2050 with their respective relative baseline demand with respect to 2014 residential annual baseline demand in the GB.

The relative baseline demand figures in Table 2 indicate changes in the future residential electricity demand. Over the 10 years from 2020 to 2030, the residential electricity demand barely increases. The Compound Annual Growth Rate (CAGR) of residential annual baseline electricity demand during the period is $0.1 \%$ as calculated by equation (2).

$$
\text { Baseline }_{\text {CAGR }}=\left[\left(\frac{\text { Baseline }_{\text {end }}}{\text { Baseline }_{\text {start }}}\right) 1 / n-1\right] \times 100 \%
$$

Where:

Baseline $_{\text {CAGR }}$ is the compound annual growth rate of the baseline electricity demand. 
Baseline $_{\text {end }}$ is the baseline electricity demand (MWh) at the end of the period.

Baseline $_{\text {start }}$ is baseline electricity demand (MWh) at the start of the period.

$n$ is the time duration of the period in years.

The two counter acting factors responsible for this trend are the increase in the number of households (DCLG, 2016) and the declining electricity demand in the residential sector (DECC, 2015). Factors responsible for the declining electricity demand in the residential sector are: (i) the decrease in the average household size (DCLG, 2016), (ii) the increase in the ownership of new and more energy efficient appliances (DBEIS, 2017a), (iii) the improved building insulation (DBEIS, 2017a) and (iv) the increase in the electricity retail prices (DBEIS, 2017b). The CAGR of residential baseline electricity demand in the periods $2030-2040$ and $2040-2050$ are $0.4 \%$ and $0.9 \%$ respectively. Over the two-decade interval, the number of households keeps increasing (DCLG, 2016) whereas average household size and ownership of new and more energy efficient appliances figures are settling (DCLG, 2016; DBEIS, 2017a). This explains the rise in the CAGR from $0.4 \%$ to $0.9 \%$ during the periods.

The implication of low CAGR $(0.1 \%)$, in spite of the increase in the number of households between 2020 and 2030 (DCLG, 2016), is that more customers would need to be served by the Distribution Network Operators (DNOs) for disproportional and marginal increase in electricity demand in the residential sector. This condition is not business friendly and the DNOs may review residential electricity retail price upward to cover for additional resources committed to serving the increasing customers. However, with uptake of EVs and HPs the electricity demand from the residential sector is expected to increase considerably. This is because most EV owners, more than $80 \%$, find their homes to be the most convenient locations to recharge their EVs (UK Power Networks, 2014; Knight et al., 2015). With the anticipated increasing uptakes of EVs and HPs over the coming years up onto 2050, the CAGR of electricity demand from the residential sector is expected to increase rapidly over that period. Rapid increase of residential electricity demand due to EVs and HPs uptakes present the DNOs with both technical challenges and business opportunities. Technical challenges because of the concern that distribution system might be stressed, and business opportunities because consumers' energy spending is shifting from the oil and gas to the electricity industry.

\section{EVs Uptake Projections in the LV Network}

The projected future number of cars in the GB up unto 2050 is first calculated. The calculation of the projected future number of cars in the GB is based on extrapolation from historical data of the number of cars in the GB (DVLA/DfT, 2018), population of the GB (ONS, 2017b), and the number of households in the GB (DCLG, 2016; ONS, 2017a). Figure 2 and Figure 3 show the trend in average household size, cars per household and cars per head of population in the GB between 1994 and 2017.

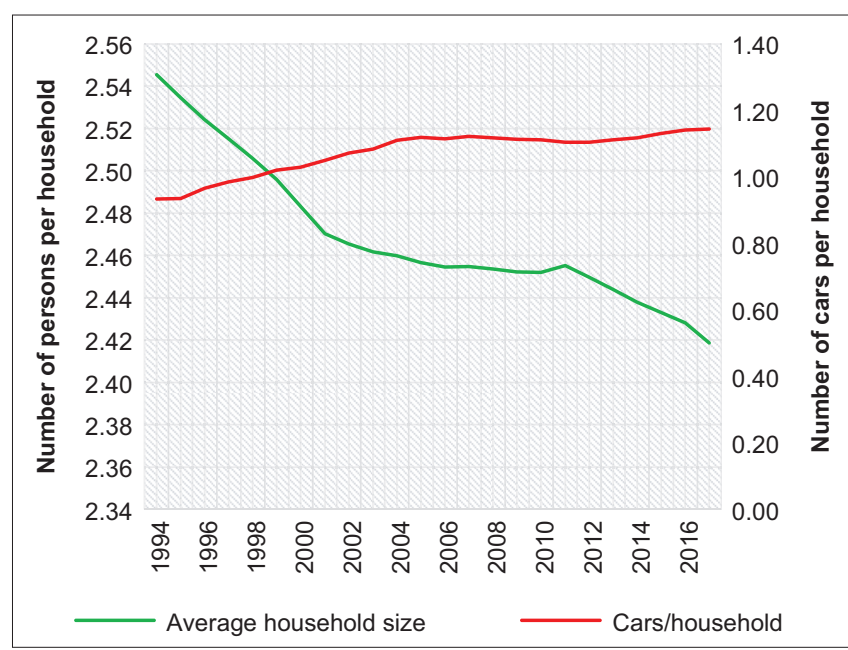

Figure2: Averagehousehold sizeand cars perhousehold in GB, 1994-2017

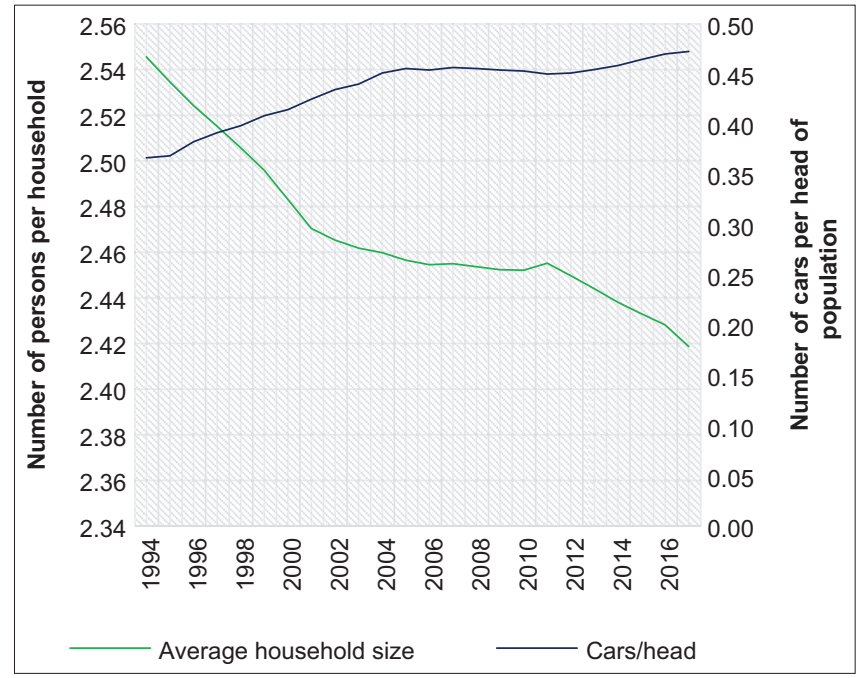

Figure 3: Average household size and cars per head of population in GB, 1994-2017

As seen from Figure 2 and Figure 3 both cars per household and cars per head of population share similar trend in their relationships with the average household size. In both cases as the average household size in GB decreased by approximately $0.4 \%$ between 1994 and 2004, cars per household and cars per head both increased by almost $2.0 \%$ in the same period.

Many economic and social factors, which are outside the scope of the present work, could be responsible for declining trend in the average household size. However, the somewhat inverse relation between average household size and cars per household could be explained; thus, two persons of the same household sharing a car may end up with two cars if one person goes out to form another household. Therefore, in GB, car ownership (hence number of cars) is associated with number of households and household size. In the last 10 years (20072017), the average household size changed slightly by an annual decrease of $0.1 \%$. Similarly, over the same period, both cars per household and cars per head figures increased at an annual rate 
of $0.2 \%$ each. For the rest of this work, it is assumed that the average household size decreases by $0.1 \%$ annually, while cars per household and cars per head figures both increase by $0.2 \%$ annually up unto 2050.

Average household size, cars per household and cars per head of the population are calculated up unto 2050 based on this assumption. Then from projected number of households in GB (DCLG, 2016; ONS, 2017a) and the projected population (ONS, 2017b; European Commission, 2018), projected number of cars are calculated by either equation (3) or (4).

$$
\begin{gathered}
\operatorname{Cars}_{\text {projected }(y r)}=\operatorname{Cars}_{\text {perHH }(y r)} \times \mathrm{HH}_{\text {projected }(y r)} \\
\operatorname{Cars}_{\text {projected }(y r)}=\operatorname{Cars}_{\text {perH }(y r)} \times \text { Population }_{\text {projected }(y r)}
\end{gathered}
$$

Where:

Cars $_{\text {projected (yr) }}$ is the projected number of cars (Millions) in a particular year.

Cars $_{\text {perHH(yr) }}$ is the number of cars per household in a particular year.

$H H_{\text {projected }(y r)}$ is the projected number of households (Millions) in a particular year.

Cars $_{\text {perH(yr) }}$ is the number of cars per head of population in a particular year.

Population $_{\text {projected(yr) }}$ is the projected population (Millions) in a particular year.

The results of the calculations are shown in Table 3.

The percentage error between the average household size calculated based on the assumption earlier made from its relationship with cars per household and the average household size calculated from the projected population and projected number of households is less than 1\% in 2020, 2030, 2040 and 2050. The low percentage error justifies the assumption.

Projected percentage of future uptake of EVs in TD and SS scenarios are now calculated. The calculation is based on the projected number of $\mathrm{EV}$ s in GB in each scenario up unto 2050 as reported in (National Grid, 2017) and the calculated projected future number of cars up unto 2050. Table 4 shows the results of the calculation for the percentage of future uptake of $\mathrm{EVs}$.

Presently, typical household annual average electricity consumption in GB as revised in 2017 is estimated to be

Table 3: Average household size, cars/household, cars/head, pouplation, number of households and number of cars $G B$, 2020-2050

\begin{tabular}{ccccccc}
\hline Year & $\begin{array}{c}\text { Ave. } \\
\text { Household household } \\
\text { size }\end{array}$ & $\begin{array}{c}\text { Cars per } \\
\text { head }\end{array}$ & & $\begin{array}{c}\text { Cars per Population } \\
\text { (Millions) }\end{array}$ & $\begin{array}{c}\text { Number of } \\
\text { households } \\
\text { (Millions) }\end{array}$ & $\begin{array}{c}\text { Number } \\
\text { of cars } \\
\text { (Millions) }\end{array}$ \\
\hline 2020 & 2.41 & 1.15 & 0.47 & 67 & 28 & 32 \\
2030 & 2.39 & 1.17 & 0.48 & 71 & 30 & 35 \\
2040 & 2.36 & 1.19 & 0.49 & 75 & 32 & 38 \\
2050 & 2.34 & 1.21 & 0.50 & 78 & 33 & 40 \\
\hline
\end{tabular}

3100kWh (Ofgem, 2017). Typical household annual average electricity consumption has been on a declining trend since 2005 (Ofgem, 2010; Ofgem, 2013; Ofgem, 2015b; Ofgem, 2017). However, for this study, it is assumed constant at the 2017 revised value. Therefore, total number of households in the LV network can be determined by dividing its annual electricity demand by typical household annual average electricity consumption as expressed in equation (5).

$$
L V_{\mathrm{No}_{H H(y r)}}=\frac{L V_{\text {baseline }_{\text {dmd }(y)}}}{H H_{\text {typical }_{\text {dmad(yr) }}}}
$$

Where:

$L V_{\mathrm{No}_{H H}(y r)}$ is the number of households in the $\mathrm{LV}$ network in a particular year.

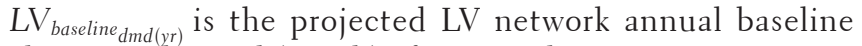
electricity demand (MWh) of a particular year.

$\mathrm{HH}_{\text {typical }}$ dmd(vr) is the typical household annual average electricity demand (MWh) in a particular year.

$y r$ is the year identifier index.

The number of future uptake of EVs in each of TD and SS scenario in the $L V$ network for a particular year is the product of the number of households in the $L V$ network, the number of cars per household and the percentage uptake of EVs for the corresponding year as expressed by equation (6).

$$
L V_{\mathrm{No}_{E V(r)}}=L V_{\mathrm{No}_{H H(r)}} \times \operatorname{Cars}_{\text {perHH}(y r)} \times \mathrm{EV}_{\% \text { uptake }(y r)}
$$

Where:

$L V_{\mathrm{No}_{\mathrm{EV}(y r)}}$ is the number of $\mathrm{EV}$ s in the $\mathrm{LV}$ network in a particular year.

$L V_{\mathrm{No}_{H H}(y r)}$ is the number of households in the $\mathrm{LV}$ network in a particular year. Cars ${ }_{\text {perHH(yr) }}$ is the number of cars per household in a particular year

$\mathrm{EV}_{\% \text { uptake(yr) }}$ is the percentage uptake of EVs in a particular year

$y r$ is the year identifier index.

Table 5 shows the results of calculation of equations (5) and (6) for the number of households and number of EVs in TD and SS scenarios.

\section{E. EVs Charging Load Requirement in the LV Network}

Average daily energy requirement of $\mathrm{EVs}$ in the $\mathrm{LV}$ network is estimated. In this work, average daily energy requirement of

Table 4: Percentage uptake of EVs, GB, 2020-2050

\begin{tabular}{ccccccr}
\hline Year & $\begin{array}{c}\text { Number } \\
\text { of cars } \\
\text { (Millions) }\end{array}$ & \multicolumn{2}{c}{$\begin{array}{c}\text { Number of } \\
\text { EVs } \\
\text { (Millions) }\end{array}$} & & & \multicolumn{2}{c}{$\begin{array}{c}\text { Percentage EV } \\
\text { uptake } \\
\text { (\%) }\end{array}$} \\
\cline { 3 - 4 } \cline { 7 - 8 } & & TD & SS & & TD & SS \\
\hline 2020 & 32.0 & 2.0 & 0.4 & & 6.3 & 1.3 \\
2030 & 35.0 & 9.0 & 2.0 & & 25.7 & 5.7 \\
2040 & 38.0 & 17.0 & 4.0 & & 44.7 & 10.5 \\
2050 & 40.0 & 25.0 & 7.0 & & 62.5 & 17.5 \\
\hline
\end{tabular}


an $\mathrm{EV}$ is defined as that amount of $\mathrm{kWh}$ by which the battery is depleted at the end of all the day's trips and by which the battery must be replenished before the start of the next day's trips. Average daily energy requirement of an EV can be quickly estimated by the product of average daily travel distance of the $\mathrm{EV}$ and the battery efficiency of the $\mathrm{EV}$ as expressed in equation (7).

$$
\mathrm{EV}_{k W h_{\text {daly }}}=\text { distance }_{\text {daily }} \times \eta_{\mathrm{EV}}
$$

Where:

$E V_{k W h_{d a i l y}}$ is the average daily energy requirement (kWh) of an EV.

distance $_{\text {daily }}$ is the average daily travel distance $(\mathrm{km})$ of an $\mathrm{EV}$. $\eta_{E V}$ is the battery efficiency $(\mathrm{kWh} / \mathrm{km})$ of $\mathrm{EV}$.

In this work, 2015 Nissan Leaf 24kWh model is chosen as the representative EV. Nissan Leaf is the most popular pure electric car in the UK (DfT, 2018b). 2015 Nissan Leaf 24kWh has a combined city and highway efficiency of approximately $0.2 \mathrm{kWh} / \mathrm{km}$ and a range of at least $120 \mathrm{~km}$ on full battery charge (Nissan Motor Corporation, n.d.). From the National Travel Survey (DfT, 2018a), average daily car travel distance in the UK is estimated to be $36 \mathrm{~km}$. Therefore, with EV efficiency and average daily car travel distance already established, an EV will need $7.2 \mathrm{kWh}$, which is $30 \%$ of the full state of charge (SoC) of the battery, as its average daily energy requirement. In the LV network, the total average daily energy requirement will be the number of $\mathrm{EVs}$ in the network multiplied by $7.2 \mathrm{kWh}$ as expressed in equation (8).

$$
L V_{E V_{k W W_{\text {dally }}}}=\sum_{i=1}^{n} E V_{i} \times 7.2
$$

Where:

$L V_{E V k W h}$ daily is the average daily $\mathrm{EVS}$ charge requirement $(\mathrm{kWh})$ of the LV network.

$n$ is the number of EVs in the LV network.

The constant 7.2 presented in (8) is the average daily energy requirement $(\mathrm{kWh})$ of an EV. Equation (8) only gives the minimum average daily EVs charge requirement of the $\mathrm{LV}$ network, since it assumes $7.2 \mathrm{kWh}$ as daily charge requirement for all EVs. In reality, this cannot be the case and can give a misleading optimistic result of the impact study. Therefore, a more realistic daily $\mathrm{EV}$ s charge requirement is proposed. It is assumed that the EV battery should not be depleted below $7.2 \mathrm{kWh}(30 \% \mathrm{SoC})$, the minimum required to guarantee daily average travel distance. This gives the range of daily charge

Table 5: Number of EVs per scenario in the Iv network

\begin{tabular}{lccc}
\hline Year & $\begin{array}{c}\text { Number of } \\
\text { households } \\
\text { (Units) }\end{array}$ & \multicolumn{2}{c}{ Number of EVs (Units) } \\
\cline { 3 - 4 } & 357 & TD & SS \\
\hline 2020 & 360 & 108 & 5 \\
2030 & 374 & 199 & 24 \\
2040 & 409 & 309 & 47 \\
2050 & & & 87 \\
\hline
\end{tabular}

Int Multidiscip Res J • 2021 • Vol 11 requirement of an EV to be between minimum of $7.2 \mathrm{kWh}(30 \%$ SoC) and maximum of $16.8 \mathrm{kWh}(70 \%$ SoC). A probability distribution function (PDF) of daily charge requirement of 100 EVs (representing $100 \%$ for easy normalization) was created with a mean of $12 \mathrm{kWh}$ and standard deviation of $3 \mathrm{kWh}$ between the minimum of $7 \mathrm{kWh}$ and maximum of $17 \mathrm{kWh}$. Figure 4 shows the daily charge requirement distribution.

From Figure 4, the more realistic daily charge requirement of EVs in the LV network is the sum product of the values of the $x$ and $y$ axes of the bars as expressed by equation (9).

$$
L V_{E V_{k W h_{d a l y}}}=\sum_{k=1}^{K} x_{k} y_{k}
$$

Where:

$L V_{E V k W h}$ daily is the average daily EVs charge requirement (kWh) of the LV network.

$K$ is the total number of bars.

$y$ is the number of $\mathrm{EV}$.

$x$ is the charge requirement ( $\mathrm{kWh})$.

$k$ is the identifier index for the bars.

The half-hourly percent of average daily charge in (National Grid, 2015) is adopted in this work to generate the actual average half-hourly EV charging profile. Data such as number of trips, start and end times of trips, average distance travelled, arrival times at homes, etc. generated from the National Travel Survey and Time Use Survey formed the basis of this charging profile (National Grid, 2015). Figure 5 shows the average half-hourly EV charging profile used in this study.

From the charging profile of Figure 5, it seen that the bulk of the charging demand takes place between 16:00 and 00:00 hours. The average peak demand for EV charging, $5.1 \%$ of average daily energy requirement, occurs at 21:00 hours.

\section{F. HPs Uptake Projections in the LV Network}

Projected percentage of future uptake of HPs in TD and SS scenarios are first calculated based on the projected number of HPs uptake in each scenario according to (National Grid, 2017) and the number of households as earlier calculated and shown in Table 3. Table 6 shows the results of the calculation for the percentage of future uptake of HPs.

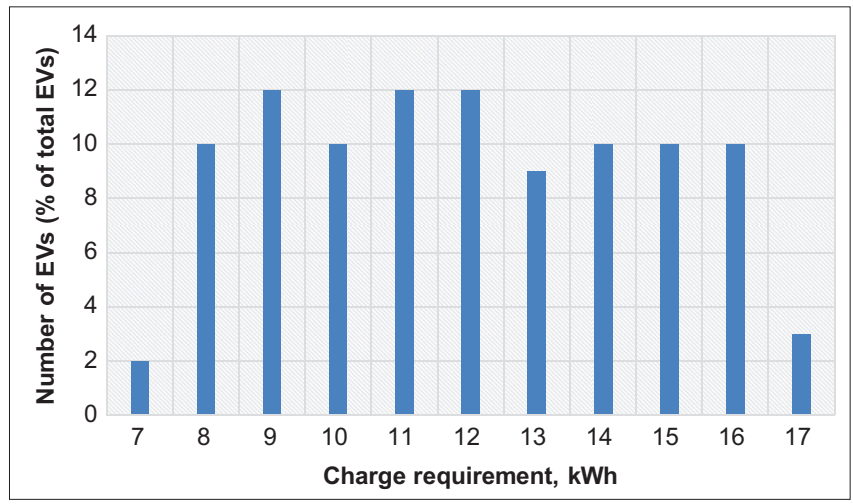

Figure 4: EVs daily charge requirement distribution 
The number of future uptake of HPs in each of TD and SS scenario in the $L V$ network for a particular year is the product of the number of households in the LV network and the percentage uptake of HPs for the corresponding year. Table 7 shows the number of HPs in TD and SS scenarios.

\section{G. Modelling the HP Operation}

The operation of variable speed Air Source Heat Pump (ASHP) providing both space heating $(\mathrm{SH})$ and domestic hot water (DHW) is modelled. The operation of variable speed ASHP is dynamic in that the heat output and the coefficient of performance (COP) of the HP vary with the heating demand of the building it is installed in and the external temperature. Figure 6, adapted from (Wemhoener, 2011), illustrates the block diagram of HP system configuration modelled in this work. The HP system configuration is such that the provision for DHW and SH are mutually exclusive. The DHW provision has priority control in the event of DHW demand and SH demand occurring at the same time. In this event, the DHW demand is met first and then the SH demand. This design configuration is the most common in the market (Wemhöner \& Afjei, 2003; Wemhöner et al., 2007; Wemhoener, 2011).

\section{H. SH Model Formulation}

The formula, as adapted from (Shao et al., 2013), for the internal air temperature of the building after a time slot $t$ is given as by:

$$
T_{i n t(t+1)}=T_{i n t(t)}-\left(Q_{\text {loss }(t)}-Q_{g a i n(t)}-H P_{S H(t)} \cdot y_{(t)}\right) \frac{\Delta t}{\Delta q}
$$

Where:

$T_{\text {int }(t+1)}$ is the internal air temperature $(o C$ or K $)$ of the building after a time slot $t$.

$T_{\text {int }(t)}$ is the internal air temperature $(o \operatorname{Cor} K)$ of the building in time slot $t$.

$Q_{\text {loss }(t)}$ and $Q_{\text {gain }(t)}$ are the heat loss $(W)$ and heat gain $(W)$ of the building in time slot $t$.

$H P_{S H(t)}$ is the heat output $(W)$ of the HP in SH mode in time slot $t$.

$y_{(t)}$ is binary variable which determines the operational status $(\mathrm{ON}=1$ or $\mathrm{OFF}=0)$ of the HP in SH mode in time slot $t$.

$\Delta t$ is the duration of the time slot in $(s)$.

$\Delta q$ is the energy needed to change the internal air temperature of the building by $1^{0} \mathrm{C}\left(\frac{\mathrm{J}}{\mathrm{oC}}\right)$.

The heat loss of a building is the sum of heat loss through the fabric of the building (floors, walls, roof, windows and doors) and the heat loss due to ventilation/infiltration (Hall \& Greeno, 2011). The heat loss, $Q_{l o s(t)}$, of the building in time slot $t$ is given by:

$$
Q_{\text {loss }(t)}=\left(\sum(A U)+0.3 N_{a c} V\right) \times\left(T_{i n t(t)}-T_{e x t(t)}\right)
$$

Where:

$U$ is thermal transmittance $\left(\frac{W}{m^{2} K}\right)$.

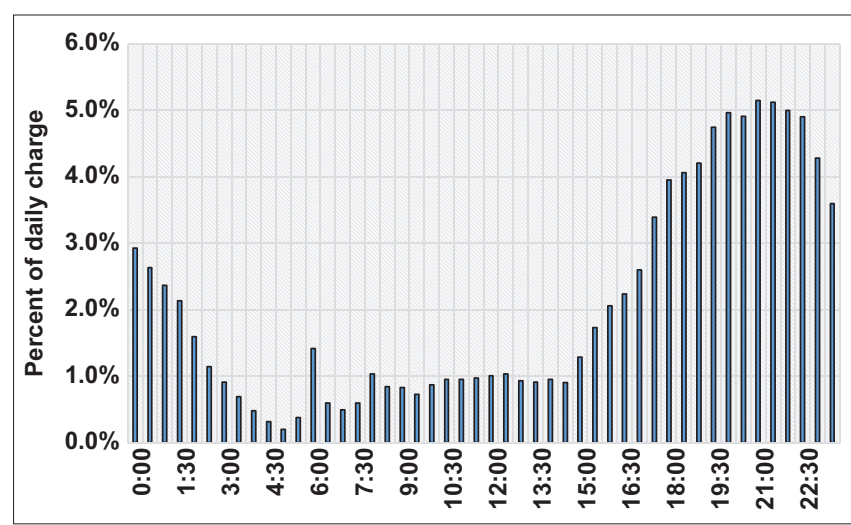

Figure 5: Average half-hourly EV charging profile (National Grid, 2015)

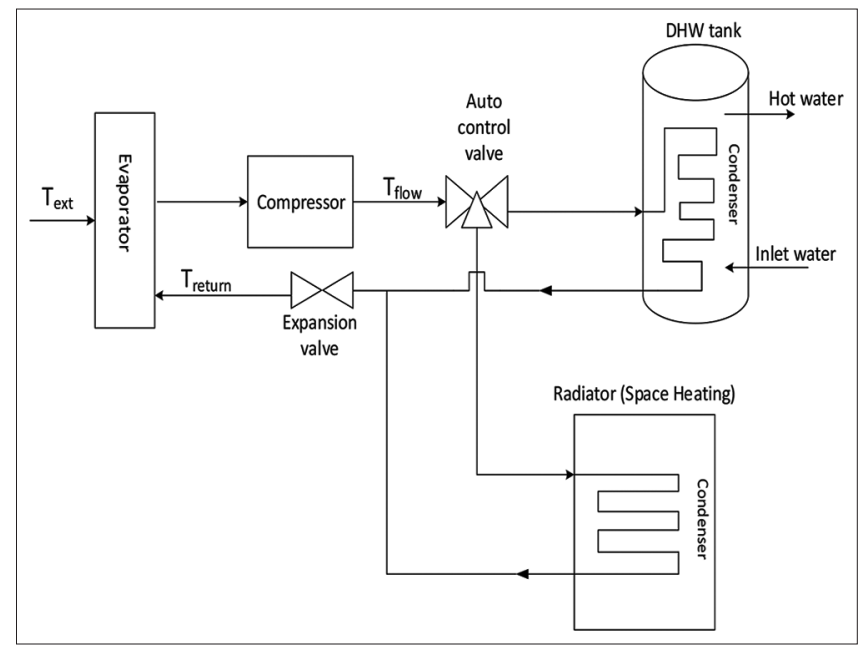

Figure 6: Block diagram of HP System Configuration (adapted from (Wemhoener, 2011))

\begin{tabular}{|c|c|c|c|c|c|}
\hline \multirow[t]{2}{*}{ Year } & \multirow{2}{*}{$\begin{array}{c}\text { Number of } \\
\text { households } \\
\text { (Millions) }\end{array}$} & \multicolumn{2}{|c|}{$\begin{array}{c}\text { Number of HPs } \\
\text { (Millions) }\end{array}$} & \multicolumn{2}{|c|}{$\begin{array}{c}\text { Percentage HP } \\
\text { uptake (\%) }\end{array}$} \\
\hline & & TD & SS & TD & $\mathrm{SS}$ \\
\hline 2020 & 28 & 0.43 & 0.24 & 1.5 & 0.9 \\
\hline 2030 & 30 & 3.74 & 0.72 & 12.5 & 2.4 \\
\hline 2040 & 32 & 8.09 & 0.86 & 25.3 & 2.7 \\
\hline 2050 & 33 & 16.69 & 0.91 & 50.6 & 2.8 \\
\hline
\end{tabular}

Table 6: Number of HPs per scenario

Table 7: Percentage uptake of HPs GB, 2020-2050

\begin{tabular}{lcc}
\hline Year & \multicolumn{2}{c}{ Number of HPs } \\
\cline { 2 - 3 } & TD & SS \\
\hline 2020 & 5 & 3 \\
2030 & 45 & 9 \\
2040 & 95 & 10 \\
2050 & 207 & 12 \\
\hline
\end{tabular}

Int Multidiscip Res J • $2021 \quad$ • Vol 11 
A is surface area through which heat transfer occurs $\left(m^{2}\right)$.

$N_{a c}$ is the number of air changes per hour $\left(\frac{a c}{h}\right)$
$V$ is the volume of the building $\left(m^{3}\right)$

$T_{\text {ext }(t)}$ is external air temperature $(o \mathrm{Cor} K)$ in time slot $t$

The heat gain, Qgain $(t)$, of the building in time slot $t$ is given by:

$\operatorname{Qgain}(t)=\left(Q_{p} \times N_{p}\right)+\left(A_{\text {SW }} \times \operatorname{SHGC} \times S_{\text {rad }(t)}\right)$

Where:

$Q_{p}$ is heat gain from one person $(W)$.

$N_{p}$ is the number of occupants.

$A_{\mathrm{SW}}^{p}$ is the area of window facing south $\left(\mathrm{m}^{2}\right)$.

SHGC is solar heat gain coefficient of window.

$S_{\text {rad }(t)}$ is solar irradiance $\left(\frac{W}{m^{2}}\right)$ in time slot $t$.

The energy needed to change the internal air temperature of the building is given by:

$$
\Delta q=C_{\text {air }} \times \rho_{\text {air }} \times V
$$

Where:

$\mathrm{C}_{\text {air }}$ is specific heat capacity of air for typical room condition

$\left(\frac{I}{K g o C}\right)$

$\rho_{\text {air }}$ is density of air $\left(\frac{\mathrm{Kg}}{\mathrm{m}^{3}}\right)$

$V$ is the volume of the building $\left(m^{3}\right)$

The operational status, $y(t)$, of the HP in SH mode is represented by:

$$
y_{(t)}=\left\{\begin{array}{c}
1=O N, T_{i n t(t)}<T_{s e t}-T_{s g} \\
0=O F F, T_{i n t(t)}>T_{s e t}+T_{s g} \\
y_{(t-1),} \quad T_{s e t}-T_{s g} \leq T_{i n t(t)} \leq T_{s e t}+T_{s g}
\end{array}\right.
$$

Where:

$\mathrm{T}_{\text {int }(t)}$ is the internal air temperature (oCor K) of the building in time slot $t$

$T_{\text {set }}$ is the set-point temperature of the internal air $(o \mathrm{CorK}$ )

$\mathrm{T}_{\mathrm{sg}}$ is the swing temperature (oCor K) of the HP in SH mode.

$y_{(t-1)}$ is the operational status of the HP in previous time slot.

In equation (14), $T_{\text {set }}$ is the desired internal air temperature and therefore the thermostat set-point. If the actual internal air temperature, $\operatorname{Tint}(t)$, drops below the temperature lower limit, $T_{\text {low }}$, which is the difference between $T_{\text {set }}$ and $T_{s g}$, then the $\mathrm{HP}$ is switched $\mathrm{ON}$ to raise the internal air temperature. Conversely, when the internal air temperature rises above the temperature upper limit $T_{u p}$, which is the sum of $T_{s e t}$ and $T_{s g}$, the HP switches OFF. However, the operational status of the HP remains unchanged if the internal air temperature is between $\mathrm{T}_{\text {low }}$ and $\mathrm{T}_{u p^{*}}$
Ignoring losses, the heat output of the HP in SH mode is equal to the radiator output which is also equal to the condenser output. That is:

$$
H P_{S H(t)}=Q_{\text {condenser }(t)}=Q_{\text {radiator }(t)}
$$

Where:

$Q_{\text {condenser }(t)}$ is the condenser heat output $(W)$ in time slot $t$. $Q_{\text {radiator }(t)}$ is the radiator heat output $(W)$ in time slot $t$.

The heat flux inside the condenser of the HP can be expressed according to (Hall \& Greeno, 2011) by:

$$
Q_{\text {condenser }(t)}=m c\left(T_{\text {flow }}-T_{\text {return }(t)}\right)
$$

Where:

$m$ is the mass flow rate $\left(\frac{\mathrm{kg}}{\mathrm{s}}\right)$ of water.

$c$ is the specific heat capacity $\left(\frac{J}{k g o C}\right)$ of water.

$T_{\text {flow }}$ is the operating temperature $(o \mathrm{Cor} K)$ of the working fluid reaching the condenser.

$T_{\text {return }(t)}$ is the temperature ( $o$ Cor $K$ ) of the working fluid leaving the condenser.

The heat output of the radiator can be expressed as:

$$
Q_{\text {radiator }(t)}=U_{\text {rad }} A_{\text {rad }}\left(T_{\text {rad }(t)}-T_{\text {int }(t)}\right)
$$

Where:

$U_{\text {rad }}$ and $A_{\text {rad }}$ are the heat transmission coefficient $\left(\frac{W}{m^{2} K}\right)$ and
surface area $(m 2)$ of the radiator respectively. $T_{i n t(t)}$ is the internal air temperature (oCor $K$ ) of the building in time slot $t$.

$T_{\text {rad }(t)}$ is the radiator temperature $(o \operatorname{Cor} K)$ and is given by:

$$
T_{\text {rad }(t)}=\frac{T_{\text {flow }}+T_{\text {return }(t)}}{2}
$$

From (15), (16), (17) and (18) the return temperature, $T_{\text {return(t) }}$, can be expressed as:

$$
T_{\text {return }(t)}=\frac{T_{\text {flow }}\left(2 m c-U_{\text {rad }} A_{\text {rad }}\right)+2 U_{r a d} A_{r a d} T_{\text {int }(t)}}{U_{\text {rad }} A_{\text {rad }}+2 m c}
$$

Based on test data, from the Heat Pump Test Centre WPZ, of 30 different models of ASHPs (Wärmepumpen-Testzentrum WPZ, 2013), the expression for the COP of HP can be deduced from the plot of COP against ' $\mathrm{T}_{\text {return }}-\mathrm{T}_{\text {ext }}$ ' with a 
coefficient of determination $\left(R^{2}\right.$ value $)$ of 0.9797 by the following equation:

$$
\mathrm{COP}_{(t)}=7.90471 e^{-0,024\left(T_{\text {return }(t)}-T_{\text {ext }(t)}\right)}
$$

Where:

$\mathrm{COP}_{(t)}$ is the coefficient of performance of the HP at time slot $t$. $T_{e x t(t)}$ is the external air temperature $(o C o r K)$ at time slot $t$.

The COP- curve, which is here defined as the plot of COP against ' $T_{\text {return }}-T_{\text {ext }}$ ' derived from the test data, is shown in Figure 7. In Figure 7, there are 9 test points and the COP at a point is the average of COPs of 30 ASHPs at that point.

The actual electrical input, $P_{S H}$ elect $(t)(W)$, for the operation of the HP in SH mode is therefore given by:

$$
P_{S H_{\text {elect }(t)}}=\frac{H P_{S H(t)}}{C O P_{(t)}}
$$

Two temperature regimes were used in the modelling. The set-point temperature, ${ }_{\text {set }}$ of the HP between 00:00 hours and 10:30 hours is $18^{\circ} \mathrm{C}$ with a swing temperature, $T_{s g}$, of $2^{\circ} \mathrm{C}$. Whereas $T_{\text {set }}$ between 11:00 hours and 23:30 hours is $20.5^{\circ} \mathrm{C}$ with a $T_{s g}$ of $3^{\circ} \mathrm{C}$.

\section{DHW Model Formulation}

Here, the formulation of the model that describes the heat balance and temperature flow inside the hot water tank is developed. In the model formulation, single-node state is assumed since there is no occurrence of draw event large enough to trigger the transition from single-node state into two-node state. A hot water tank remains in single-node state and only changes into two-node state when a considerable volume of water is drawn in a usage event which occurs in a short interval of time ( $\mathrm{Nel}$ et al., 2018). In single-node state, the water in the tank is considered as a single mass of body with the heat and temperature of the water uniformly distributed. That is the water in the tank is not stratified after a draw event into upper layer warm water and lower layer cold water from the inlet that replaces the drawn water. Figure 8 shows the DHW tank in single-node state as modelled in this work.

The temperature, $T_{(t)}$, of the water leaving the tank is the average temperature of the hot water inside the tank. The tank is refilled with inlet water at temperature, $T_{i n}$, to replace the drawn water. The inlet water mixes with the hot water inside the tank and a new average temperature, $T_{(t+1)}$, is formed for the next water draw event. The heat $(W)$ available inside the tank after a water draw event in time slot $t$ can be expressed in terms of heat balance equation as follows:

$$
Q_{(t+1)}=Q_{(t)}-Q_{u s e(t)}-Q_{a m l(t)}+H P_{D H W(t)} \cdot z_{(t)}
$$

Where:

$Q_{(t+1)}$ is the heat $(W)$ remaining after a water draw event. $Q_{(t)}$ is the heat $(W)$ available before the water draw event. $Q_{u s e(t)}$ is the heat $(W)$ loss due to the water draw event.

$Q_{a m l(t)}$ is the heat $(W)$ loss to the ambience due to heat dissipation from the tank to the environment.

$H P_{D H W(t)}$ is the heat output $(W)$ of the HP in DHW mode in time slot $t$.

$z_{(t)}$ is binary variable which determines the operational status $(\mathrm{ON}=1$ or $\mathrm{OFF}=0)$ of the HP in DHW mode in time slot $t$.

The heat balance equation in (22) can be written in terms of volume and change in temperature as follows:

$$
\begin{aligned}
& \frac{V c\left(T_{(t+1)}-T_{i n}\right)}{60 t}=\frac{V c\left(T_{(t)}-T_{\text {in }}\right)}{60 t}-\frac{V_{u s e(t)} c\left(T_{(t+1)}-T_{i n}\right)}{60 t}- \\
& U_{t a} A_{t a}\left(T_{(t)}-T_{\text {int }(t)}\right)+\frac{V c\left(T_{\text {flow }}-T_{\text {return }(t)}\right)}{60 t} \cdot z_{(t)}
\end{aligned}
$$

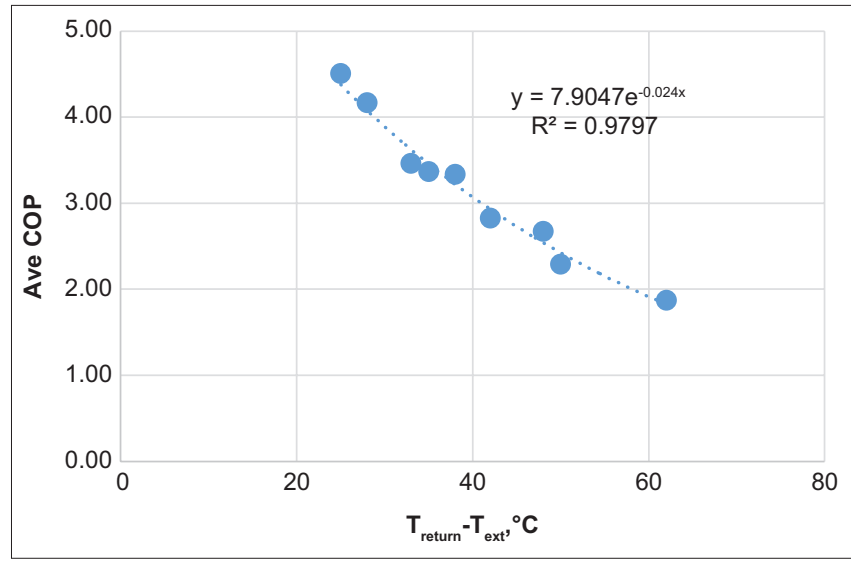

Figure 7: The COP-curve adapted from test data at HP Test Centre WPZ (Wärmepumpen-Testzentrum WPZ, 2013)

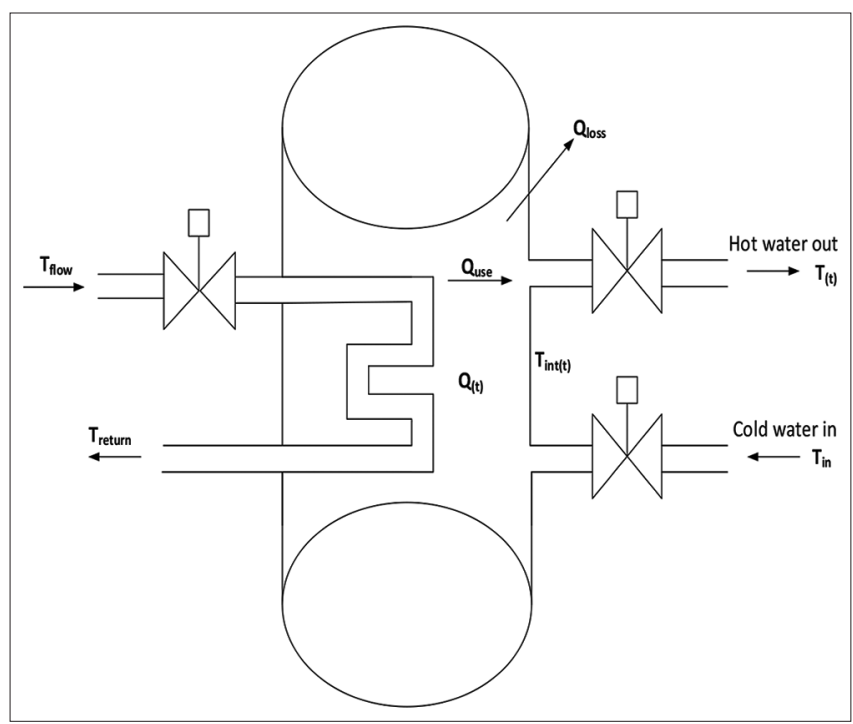

Figure 8: DHW tank in single-node state 
Where:

$\mathrm{V}$ is the volume $(l)$ of the tank. Vuse $e_{(t)}$ is the volume $(l)$ of the hot water used in time slot $t . T_{(t)}$ is the temperature $(o C$ or $K)$ of hot water inside the tank in time slot $t . T_{(t)}$ is also equal to the return temperature, Treturn $(t)$, of the working fluid. $T_{(t+1)}$ is the temperature $(o \mathrm{Cor} K)$ of hot water inside the tank after the water draw event. $T_{i n}$ is the temperature (oCorK) of the inlet cold water. $U_{t a}$ and $A_{t a}$ are the heat transmission coefficient $\left(\frac{W}{m^{2} K}\right)$ and the surface area $\left(m^{2}\right)$ of the tank respectively. $c$ is the specific heat capacity of water $4.184 \frac{\mathrm{kJ}}{\mathrm{kgoC}}$. Tint ${ }_{(t)}$ is the internal air, that is the ambient temperature (oCor K) of the building in time slot $t . \mathrm{T}_{\text {flow }}$ is the operating temperature $(o \mathrm{Cor} \mathrm{K})$ of the working fluid. $t$ is the duration of the time slot in minutes.

The operational status, $z_{(t)}$, of the HP in DHW mode is represented as follow:

$$
z_{(t)}=\left\{\begin{array}{c}
1=O N, T_{(t)}<T_{s e t(W)}-T_{s g(W)} \\
0=O F F, T_{(t)}>T_{s e t(W)}+T_{s g(W)} \\
z_{(t-1),} T_{s e t(W)}-T_{s g(W)} \leq T_{(t)} \leq T_{s e t(W)}+T_{s g(W)}
\end{array}\right.
$$

Where:

$T_{(t)}$ is the temperature (oCor K) of hot water inside the tank time slot $t$.

$T_{\text {set(W) }}$ is the set-point temperature $(o \mathrm{Cor} K)$ of hot water inside the tank.

$T_{s g(W)}$ is the swing temperature (oCor K) of the HP in DHW mode.

$z_{(t-1)}$ is the operational status of the HP in previous time slot.

Substituting for constant and solving for $T_{(t+1)}$ in (23) yields:

$$
\begin{array}{r}
V T_{(t)}+V_{\text {use }(t)} T_{\text {in }}-0.0143 t U_{t a} A_{t a} \\
T_{(t+1)}=\frac{\left(T_{(t)}-T_{\text {int }(t)}\right)+V\left(T_{\text {flow }}-T_{(t)}\right) \cdot z_{(t)}}{\left(V+V_{\text {use }(t)}\right)}
\end{array}
$$

The set-point temperature, $\mathrm{T}_{\text {set }(\mathrm{W})}$, of the $\mathrm{HP}$ for $\mathrm{DHW}$ is $50^{\circ} \mathrm{C}$ with a swing temperature, $T_{s g(W)}$, of $5^{\circ} \mathrm{C}$. The hot water setpoint temperature and the swing temperature are such that will prevent the growth of Legionella bacteria inside the tank. Legionella bacteria mostly thrives in the temperature range between $20 \circ \mathrm{C}$ and $45 \circ \mathrm{C}$ (HSE, 2014).

The COP of the HP while working in DHW mode is as expressed in (20) with $T_{\text {return(t) }}$ substituted by $T_{(t)}$. The actual electrical input, $P_{D_{W H} \text { elect }(t)}(W)$, for the operation of the HP in DHW mode is given by:

$$
P_{\mathrm{DWH}_{\text {elect }(t)}}=\frac{H P_{\mathrm{DHW}(t)}}{\mathrm{COP}_{(t)}}
$$

\section{J. HP Model Implementation}

A 6-kW heat output capacity, variable-speed ASHP with a COP of 2.7 at test condition A-7/W35 and R407C as refrigerant
(Wärmepumpen-Testzentrum WPZ, 2013) was modelled. The HP operational model as SH and DHW provider was implemented in MATLAB for a typical winter weekday and a typical summer weekday. Figure 9 is the block diagram of the implementation process of the model. Inputs to the model in the SH mode are time series external air temperature, time series solar radiation, thermostat set-point for the desired internal air temperature, SH swing temperature and the time series internal air temperature which is fed back from the output. These input parameters interact with intrinsic properties of the building (such as size of building, areas of building fabrics and U-values of building fabrics), number of occupants and the COP-curve of the HP to produce outputs in the SH mode.

In the DHW mode, the inputs are time series external air temperature, time series internal air temperature, temperature of inlet water, thermostat set-point for the desired hot water temperature, DHW swing temperature, time series water usage profile and the hot water temperature which is fed back from the output. The tank parameters like volume, surface area and heat transmission coefficient interact with the input parameters to produce outputs in the DHW mode.

The outputs of the model depend on the mode of the HP (SH mode or DHW mode) which is active in a time slot. The outputs of the model in SH mode are internal air temperature and the electricity consumption of the HP in that mode while the outputs in DHW mode are hot water temperature and the electricity consumption of the HP in that mode. The electricity consumption of the HP in a time slot $t$ is determined by the following:

$$
H P_{\text {elect }(t)}=P_{S H_{\text {elect }(t)}} \cdot y_{(t)}+P_{D W H_{\text {elect }(t)}} \cdot z_{(t)}
$$

Equation (28) ensures that the HP can only operate either in SH mode or DHW mode at a given time slot.

$$
y_{(t)} \cdot z_{(t)}=0
$$

The model is run with 100 buildings. Each building is considered as a single zone in the modelling process. In order to achieve diversity in the operation of the HPs in different buildings, the following input parameters of the model are randomized: building size, number of occupants, SHGC of windows, number of air change, initial internal air temperature and initial hot water temperature.

Figure 10 shows the profiles of the HPs average electricity demand on a typical winter weekday and a typical summer weekday. Peaks are observed at about 7:30 and 9:30 in the morning for both typical winter weekday and typical summer weekday average electricity demand of the HPs.

\section{K. HP Model Validation}

To validate the developed HP operational model, empirical data from credible sources were used as inputs to run the model. The model outputs, typical winter weekday and typical summer weekday average electricity demand of HPs expressed 


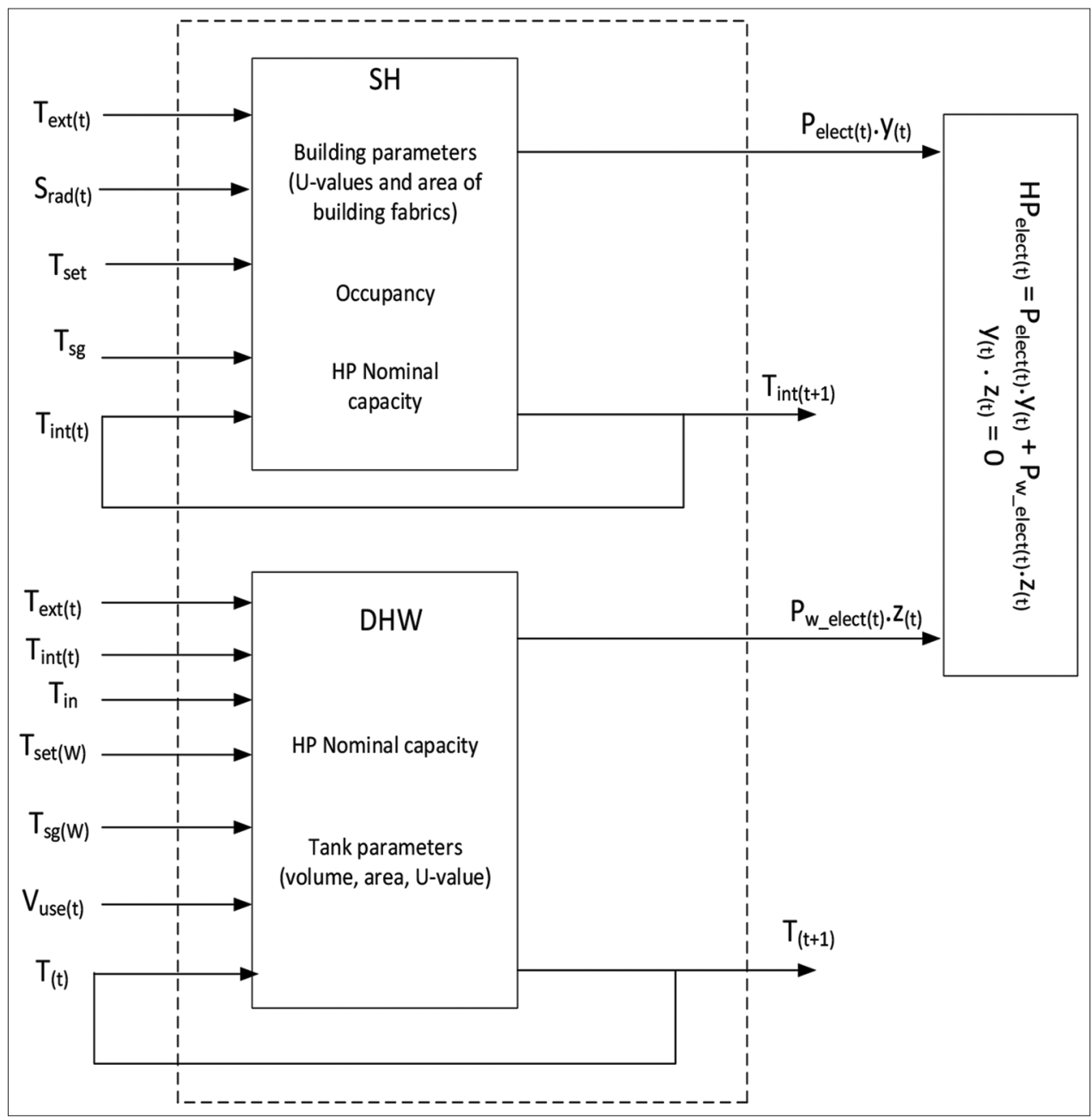

Figure 9: Block diagram of implementation process of HP operation

in half-hourly intervals, were compared with the measured daily average electricity demand of HPs in the Carbon, Control and Comfort (CCC) project (Boait \& Stafford, 2011). The comparison between the model outputs and the actual measured outputs of the CCC project showed close similarity in trends and $\mathrm{kW}$ values of the HPs daily average electricity demand profile. This gives reasonable credence to the usefulness of the developed model.

Figure 11 is the screenshot from CCC Project of average HP demand. The midnight peak observed in Figure 11 but not in Figure 10 is due to the fact that the HPs in the CCC project operate a weekly pasteurization cycle (raising the DHW temperature above $60^{\circ} \mathrm{C}$ to kill Legionella bacteria) which always takes place at midnight.

\section{Data Sources}

Empirical data of the input variables used in the modelling of HP operation were carefully sourced for. Decision on the number of occupants per household was based on (ONS, 2017a). Average daily DHW requirement of household in litres/day was estimated in line with technical guidelines from (Henderson \& Hart, 2015 ) and it is given by $25 N_{p}+36$. Normalized DHW tapping

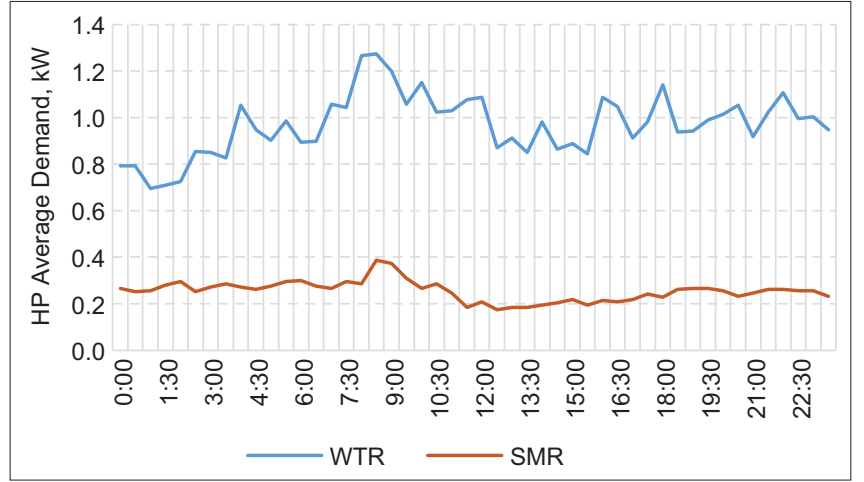

Figure 10: HP daily average demand

profile from (Hendron \& Burch, 2008) was used to estimate the actual DHW draw at any time of the day. Figure 12 illustrates the normalized DHW tapping profile. Data on geometric and constructional characteristics of the hot water tank came from (Kingspan (UK), 2016). Data about buildings parameters which consist of building type and size and $\mathrm{U}$ - values of building elements were from (DCLG, 2015) and (HM Government, 2010) respectively. Weather data were from (UK Met Office, n.d.). 


\section{NETWORK MODELLING AND SIMULATION IMPLEMENTATION}

The loads were modelled using the 'exact lumped load model' as described in (Kersting, 2012). This model is useful in situation where the locations and sizes of the loads are unknown, providing reasonable results for the line losses and voltage drop along a feeder. In exact lumped load model, one-third of the load is placed at the end of the line and two-thirds of the load is placed one-fourth of the way from the source end. The EVs and the HPs are distributed amongst the feeders based on the ratio of the number of buildings per feeder. Table 8 below shows the EVs and HPs distribution. The components (lines and transformer) of the $L V$ network were modelled in GridLAB-D power system simulation software.

Table 8: EVs and HPs distribution

\begin{tabular}{|c|c|c|c|c|}
\hline Feeder & Year & Scenario & No of EVs & No of HPs \\
\hline \multirow[t]{8}{*}{1} & 2020 & TD & 8 & 1 \\
\hline & & SS & 1 & 1 \\
\hline & 2030 & TD & 34 & 14 \\
\hline & & SS & 7 & 3 \\
\hline & 2040 & TD & 63 & 31 \\
\hline & & SS & 15 & 3 \\
\hline & 2050 & TD & 99 & 66 \\
\hline & & SS & 28 & 4 \\
\hline \multirow[t]{8}{*}{2} & 2020 & TD & 5 & 1 \\
\hline & & SS & 1 & 1 \\
\hline & 2030 & TD & 19 & 8 \\
\hline & & SS & 4 & 1 \\
\hline & 2040 & TD & 34 & 16 \\
\hline & & SS & 8 & 2 \\
\hline & 2050 & TD & 53 & 36 \\
\hline & & SS & 15 & 2 \\
\hline \multirow[t]{8}{*}{3} & 2020 & TD & 10 & 2 \\
\hline & & SS & 2 & 1 \\
\hline & 2030 & TD & 44 & 18 \\
\hline & & SS & 10 & 4 \\
\hline & 2040 & TD & 80 & 38 \\
\hline & & SS & 19 & 4 \\
\hline & 2050 & TD & 124 & 83 \\
\hline & & SS & 35 & 5 \\
\hline \multirow[t]{8}{*}{4} & 2020 & TD & 3 & 1 \\
\hline & & SS & 1 & - \\
\hline & 2030 & TD & 11 & 5 \\
\hline & & SS & 3 & 1 \\
\hline & 2040 & TD & 22 & 10 \\
\hline & & SS & 5 & 1 \\
\hline & 2050 & TD & 33 & 22 \\
\hline & & SS & 9 & 1 \\
\hline
\end{tabular}

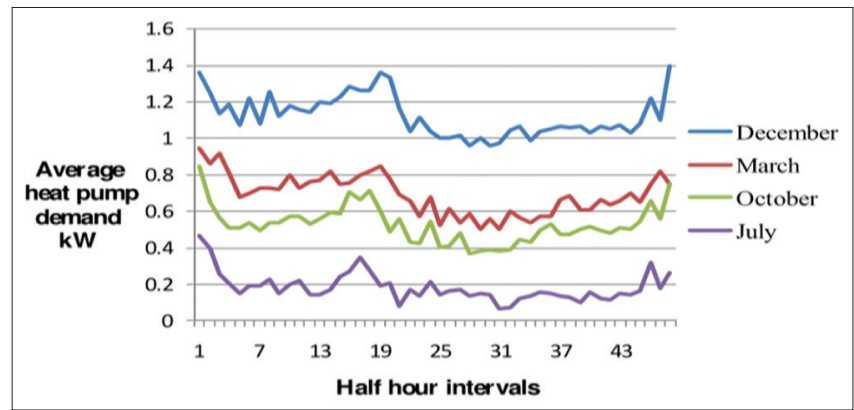

Figure 11: Screenshot from CCC Project of average HP demand (Boait \& Stafford, 2011)
Power flow calculations of the $\mathrm{LV}$ network were performed using the power flow module of the GridLAB-D software. The GridLAB-D power flow simulation was run for twenty-four hours with half-hourly resolution for a typical winter weekday and a typical summer weekday for the years 2020, 2030, 2040 and 2050 under the TD and SS scenarios. For the simulation, NewtonRaphson power flow solver was chosen, and the results were output in comma separated values (CSV) format for further analysis.

\section{SIMULATION RESULTS}

The impacts of the electricity load profiles of EVs and HPs on transformer loading, voltage profiles of the feeders and ampacity loading of the cables were evaluated in the power flow simulation of the LV distribution network. The results of the transformer loading profiles of the LV network for the four scenarios for the years 2020, 2030, 2040 and 2050 are as presented in Figures 13 (a-d) with the solid bold red line indicating the nominal capacity of the transformer in percentage.

In all the scenarios for all the years considered, there is a common trend of load build up in the early morning and in the early evening. The trend is, however, more pronounced in the $\mathrm{WtrWd}$ scenarios than in the SmrWd scenarios. The early morning load build up crests between 08:00 hours and 09:00 hours, while the early evening load build up crests between 18:00 hours and 19:00 hours. The early morning load build up can be explained due to the increased usage of hot water and hence more operation of HPs at that time of the day. Figure 10 and Figure 12 allude to this plausible explanation. However, the more pronounced early evening load build up can be attributed to the combination of increasing EV charging as people are returning home from work and increased HPs demand triggered by the slightly increased hot water usage at that time of the day. Figure 5, Figure 10, and Figure 12 support this explanation.

Up until 2040, the transformer can withstand the load requirement of the $\mathrm{LV}$ area network in all scenarios as seen in Figures 13 (a) - (c). However, a continual increase in the transformer loading is observed from 2020 through 2040. The increase is most evident in the TDWtrWd scenario, increasing from $62 \%$ of the transformer nominal capacity at 18:00 hours in

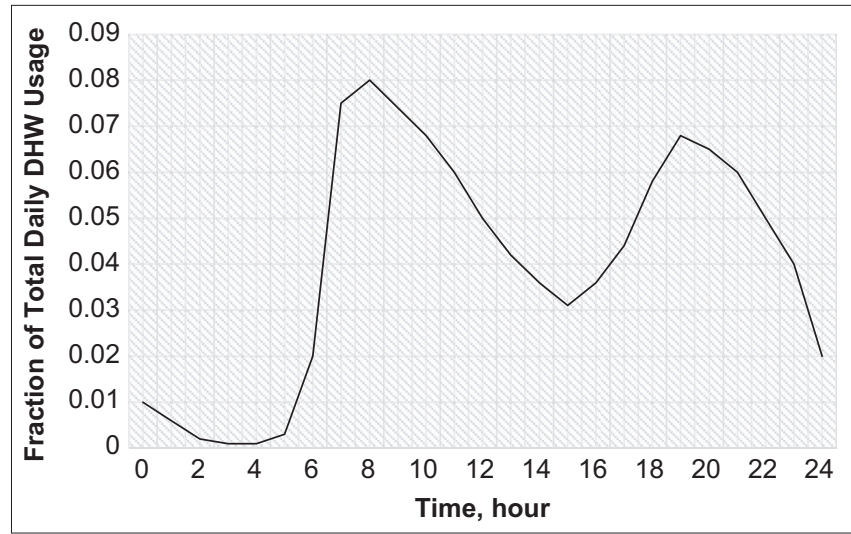

Figure 12: Normalized DHW tapping profile (Hendron \& Burch, 2008) 


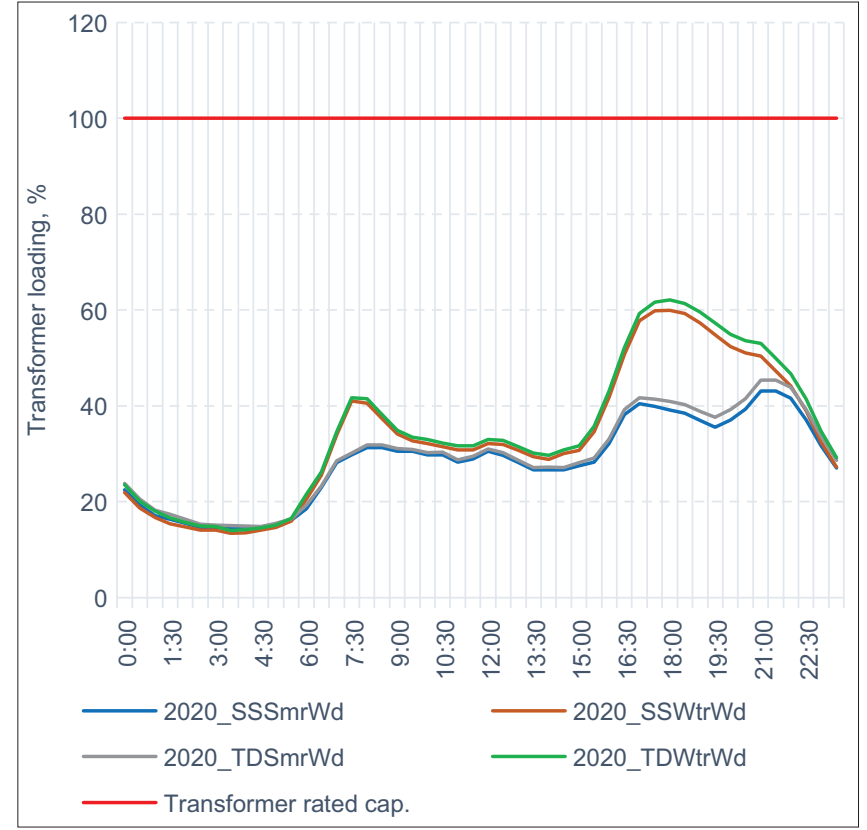

Figure 13(a): Half-hourly Percentage Transformer Loading of the LV network, 2020

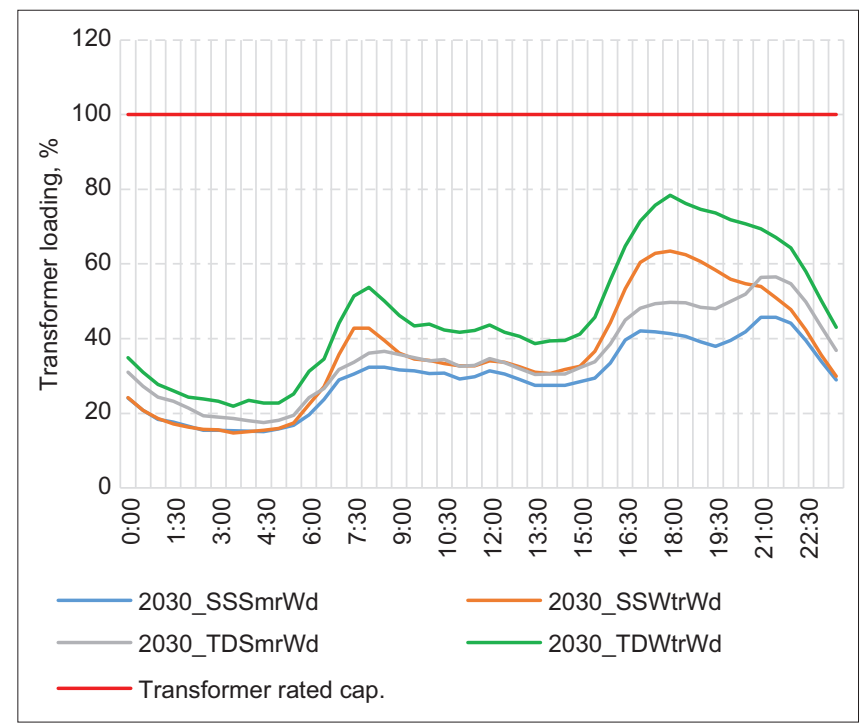

Figure 13(b): Half-hourly Percentage Transformer Loading of the LV network, 2030

2020 to $100 \%$ of the transformer nominal capacity at 18:00 hours in 2040. By 2050, as seen in Figure 13(d), the overloading of the transformer in the TDWtrWd scenario is significant. In this scenario, the nominal capacity of the transformer is exceeded on two instances. The transformer is first slightly overloaded by about $4 \%$ between 08:00 hours and 09:00 hours. Then from 17:30 hours the transformer is subjected to a sustained overload of about $30 \%$ for not less than five hours. This is the most critical scenario, and it is going to be the focus of further interest.

In Figure 14 the voltage profiles at the farthest end of all the feeders in 2050_TDWtrWd scenario are presented with the solid bold red line indicating the statutory limit for voltage drop in per unit. There

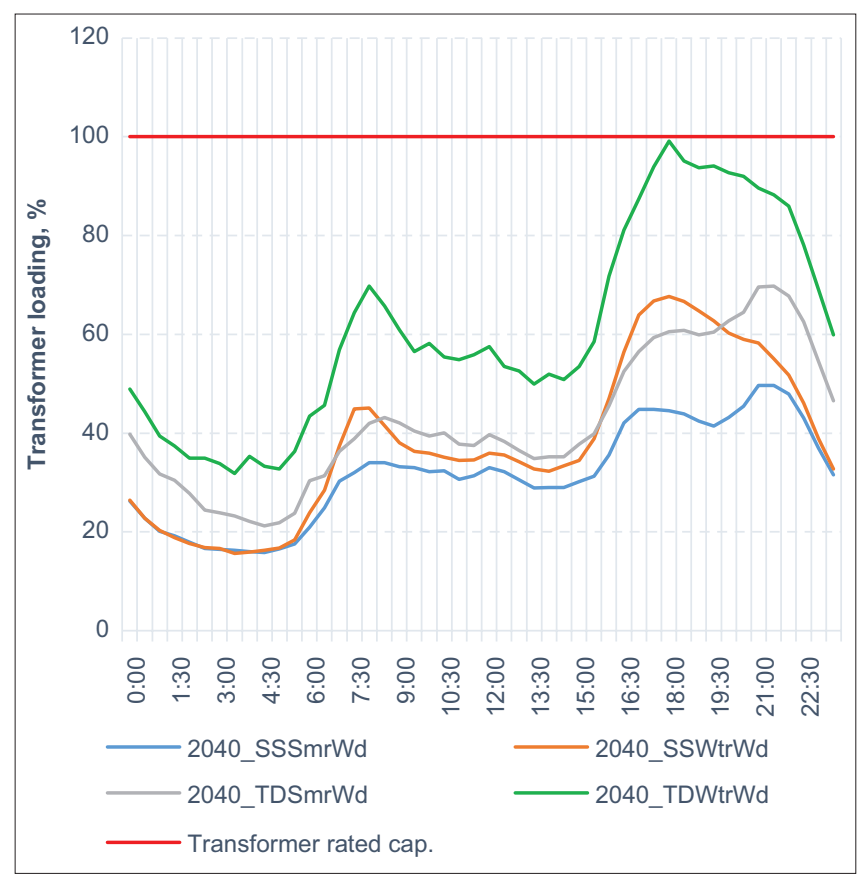

Figure 13(c): Half-hourly Percentage Transformer Loading of the LV network, 2040

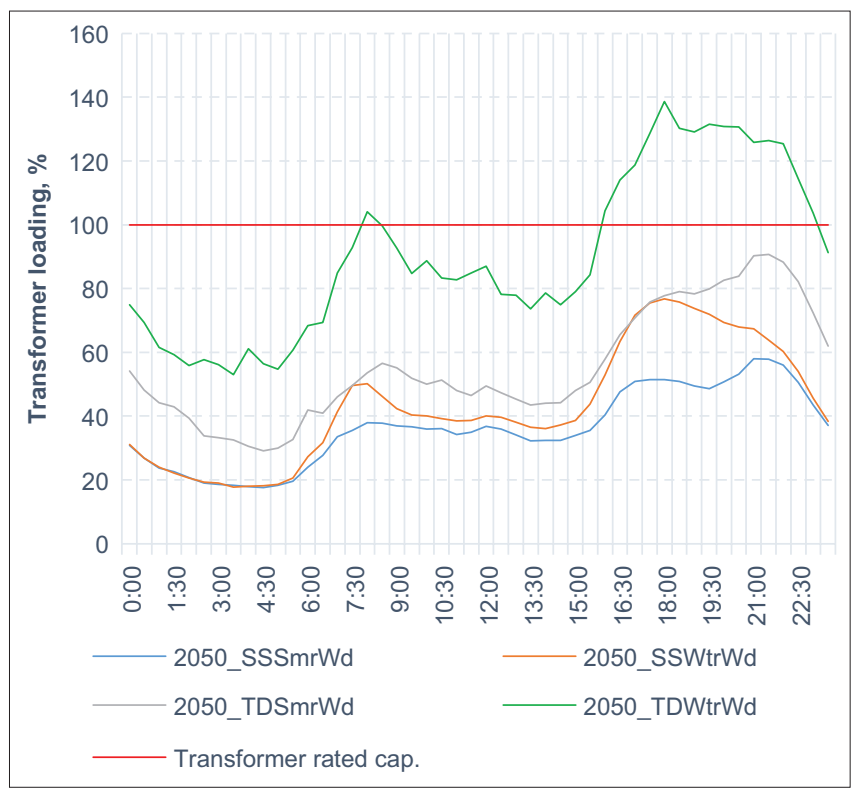

Figure 13(d): Half-hourly Percentage Transformer Loading of the LV network, 2050

is no violation of voltage drop limit in any of the feeders. The voltage profiles of the feeders follow the same trend with two notable dips at 08:00 hours and 18:00 hours. The greatest dip in voltage of value 0.96 p.u. occurs at the far end of Feeder 1 at 18:00 hours.

To observe the impact of the load profiles of EVs and HPs on thermal loading capacity of cables, percentage ampacity loading of the first cable of the four feeders in 2050_TDW trWd scenario is examined. Figure 15 shows the percentage ampacity loading of the first cable of the feeders in 2050_TDWtrWd scenario with the solid bold red line indicating the nominal ampacity of the cables in percentage. 


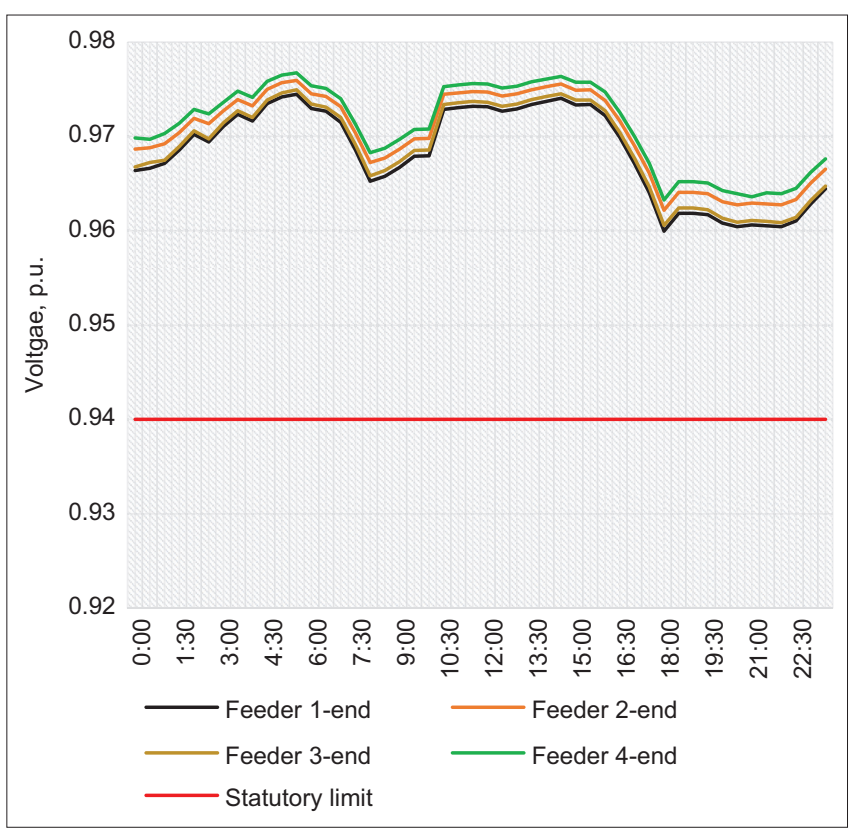

Figure 14: Voltage profiles at the farthest end of feeders in 2050_ TDWtrWd

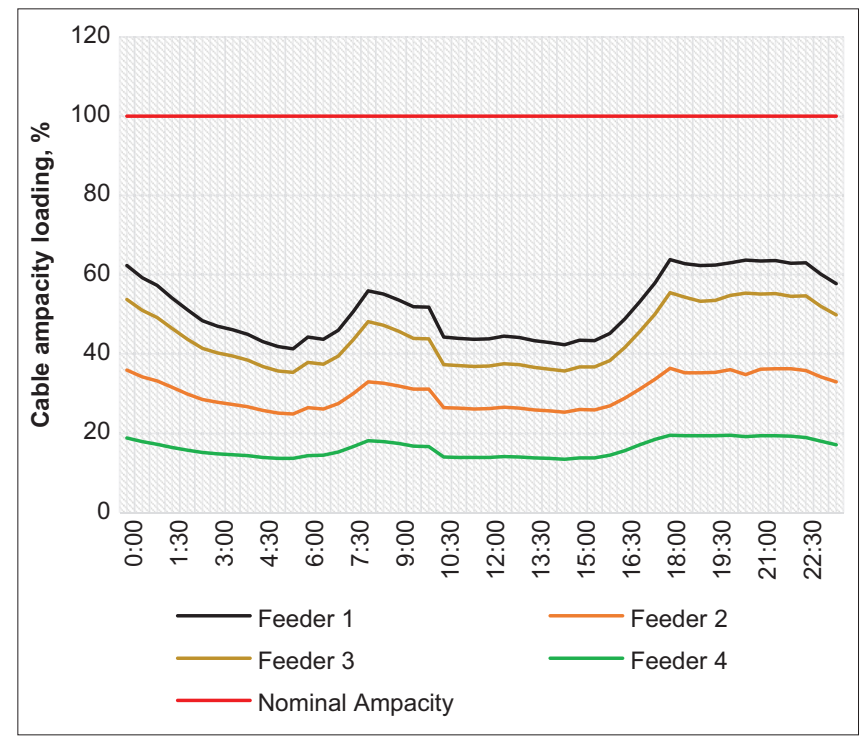

Figure 15: Percentage ampacity loading of feeders in 2050_TDWtrWd

There is no cable that is loaded beyond its ampacity rating. The most loaded cable is the first cable in Feeder 1; reaching approximately $64 \%$ of its nominal ampacity at 18:00 hours.

\section{SUMMARY AND CONCLUSION}

The impacts of future uptake and electricity load profiles of $\mathrm{EVs}$ and HPs on LV distribution networks in GB were investigated. A typical real residential urban $\mathrm{LV}$ distribution network was used as the case study. Four scenarios were formulated based on the season and projected uptake of EVs and HPs in the years 2020, 2030, 2040 and 2050. Calculations were made by scaling down the national projected number of EVs and HPs to estimate the uptake of EVs and HPs in the case study LV distribution network. Average minimum daily energy requirement of an EV was estimated to be $7.2 \mathrm{kWh}$ and the possible maximum daily energy requirement was estimated to be $16.8 \mathrm{kWh}$. Average electricity demand profiles of HP for a typical winter weekday and a typical summer weekday were created by modelling the operation of HP and implementing the model in MATLAB. The modelled operation of the HP was validated against an actual field trial project.

For all the scenarios in all the years considered, power flow simulations of the $\mathrm{LV}$ area distribution network were carried out using GridLAB-D, an agent-based power system simulation software. The results of the simulations revealed the impacts of the uptake and load profiles of EVs and HPs on the LV network in terms of transformer loading, voltage profiles of the feeders and the ampacity loading of the cables.

Results showed no violation of voltage drop limit in any of the feeders in all the scenarios for all the years considered. Also, no cable was thermally overloaded in all the scenarios for all the years considered. In terms of transformer loading, the results showed that the transformer could withstand the load requirement of the LV network in all scenarios up until 2040. However, by the winter of 2050 under the most optimistic uptake level scenario of EVs and HPs (i.e., 2050_TDWtrWd), the transformer was subjected to a sustained overload of about $30 \%$ above its nominal rating from early evening for about five hours.

Therefore, the results of this study indicated that the first possible factor that may restrict further uptake of EVs and HPs at residential LV distribution networks is the issue of transformer overloading. Overloading of transformers will be an issue of concern to the DNOs considering the importance of transformers in the overall system reliability and their replacement cost. One direct solution to addressing the concern of overloading of transformers at LV distribution networks due to increasing uptake of EVs and HPs is the upgrading of the transformers' capacities. However, the number of such transformers to be upgraded and the resources needed could be additional sources of concern to the DNOs. Other cost-effective solutions, which encourage optimal utilization of the existing transformers capacities, must be exploited.

\section{ACKNOWLEDGEMENTS}

Rilwan Oliyide would like to acknowledge the Nigeria Tertiary Education Trust Fund (TETFund) for sponsoring his Ph.D. in Cardiff University. He also would like to appreciate Moshood Abiola Polytechnic (MAPOLY), Abeoukta, Nigeria for the support received during his Ph.D. studies.

\section{REFERENCES}

Akmal, M., Fox, B., Morrow, J. D., \& Littler, T. (2014). Impact of heat pump load on distribution networks. IET Generation, Transmission \& Distribution, 8(12), 2065-2073. https://doi.org/10.1049/ietgtd.2014.0056 
Awadallah, M. A., Singh, B. N., \& Venkatesh, B. (2016). Impact of EV Charger Load on Distribution Network Capacity: A Case Study in Toronto. Canadian Journal of Electrical and Computer Engineering, 39(4), 268-273. https://doi.org/10.1109/CJECE.2016.2545925

Boait, P., \& Stafford, A. (2011). Electrical Load Characteristics of Domestic Heat Pumps and Scope for Demand Side Management. International Conference on Electricity Distribution, 21(0125), 6-9. Retrieved from http://www.cired.net/publications/cired2011/part1/papers/ CIRED2011_0125_final.pdf

Committee on Climate Change (CCC). (2015). The Fifth Carbon Budget: The next step towards a low-carbon economy. Committee on Climate Change, London.

Department of Energy and Climate Change (DECC). (2015). Digest of United Kingdom Energy Statistics 2015. Digest of United Kingdom Energy Statistics (DUKES) 2015. https://doi.org/10.1016/B978-0-12088759-0.00001-8

Department for Business Energy and Industrial Strategy (DBEIS). (2016). THE RENEWABLE HEAT INCENTIVE: A REFORMED SCHEME. London.

Department for Business Energy and Industrial Strategy (DBEIS). (2017a). Energy consumption in UK. UK Government (Vol. 112). https://doi. org/10.1073/pnas.1423686112

Department for Business Energy and Industrial Strategy (DBEIS). (2017b). Quarterly Energy prices tables annex, December 2017.

Department for Business Energy and Industrial Strategy (DBEIS). (2018). 2016 UK Grenhouse Gas Emissions, Final Figures. Statistical Release: National Statistics. London. Retrieved from https://www. gov.uk/government/uploads/system/uploads/attachment data/ file/604408/2016_Provisional_Emissions_statistics.pdf

Department for Communities and Local Government (DCLG). (2015). Housing Stock profile, 2014-15.

Department for Communities and Local Government (DCLG). (2016). Table 401: Household projections, United Kingdom, 1961-2039.

Department for Transport (DfT). (2017). Vehicle Licensing Statistics : 2016. Statistical Release, (April), 2-9.

Department for Transport (DfT). (2018a). Analyses from the National Travel Survey. Statistical Release. Retrieved from https://www.gov.uk/ government/uploads/system/uploads/attachment data/file/674568/ analysis-from-the-national-travel-survey.pdf

Department for Transport (DfT). (2018b). Vehicle Licensing Statistics: Annual 2017. Statistical Release.

DVLA/DfT. (2018). Licensed cars at the end of the year by propulsion/ fuel type, Great Britain from 1994; also United Kingdom from 2014.

European Commission. (2018). Population on $1^{\text {st }}$ January by age, sex and type of projection 2015-2080. Retrieved May 24, 2018, from http://appsso. eurostat.ec.europa.eu/nui/show.do?dataset=proj_15npms\&lang $=$ en

Farzin, H., Moeini-Aghtaie, M., \& Fotuhi-Firuzabad, M. (2016). Reliability Studies of Distribution Systems Integrated with Electric Vehicles under Battery-Exchange Mode. IEEE Transactions on Power Delivery, 31(6), 2473-2482. https://doi.org/10.1109/TPWRD.2015.2497219

Hall, F., \& Greeno, R. (2011). Building service handbook (6 $6^{\text {th }}$ ed.). Oxford: Elsevier Limited.

Health and Safety Executive (HSE). (2014). Legionnaires' disease Part 2: The control of legionella bacteria in hot and cold water systems. Health and Safety Guidance (HSG) (1 $1^{\text {st }}$ ed.). Norwich: HSE Books.

Henderson, J., \& Hart, J. (2015). BREDEM 2012 - A technical description of the BRE Domestic Energy Model (Version 1.). Wtaford: BRE. Retrieved from

Hendron, R., \& Burch, J. (2008). Development of Standardized Domestic Hot Water Event Schedules for Residential Buildings. ASME 2007 Energy Sustainability Conference, 29(August), 253-272. https://doi. org/10.1115/ES2007-36104

Hilshey, A. D., Hines, P. D. H., Rezaei, P., \& Dowds, J. R. (2013). Estimating the impact of electric vehicle smart charging on distribution transformer aging. IEEE Transactions on Smart Grid, 4(2), 905-913. https://doi.org/10.1109/TSG.2012.2217385

HM Government. (2010). The Building Regulations 2010: Conservation of fuel and power in existing dwellings - Approved Document Part L1B.

Karki, S. U., Halbhavi, S. B., \& Kulkarni, S. G. (2014). Study on Challenges in Integrating Renewable Technologies. International Journal of Advanced Research in Electrical, Electronics and Instrumentation Engineering, 3(8), 10972-10977.

Kersting, W. H. (2012). Distribution System Modeling and Analysis (3rd ed.). Florida: CRC Press.
Kingspan (UK). (2016). Vented Hot Water Cylinders. Retrieved June 26, 2016, from https://www.kingspan.com/gb/en-gb/products/hot-watercylinders/vented-hot-water-cylinders

Knight, T., Kivinen, E., \& Fell, D. (2015). Uptake of Ultra Low Emission Vehicles in the UKA Rapid Evidence Assessment for the Department for Transport. Brook Lyndhurst.

Leou, R.-C., Su, C.-L., \& Lu, C.-N. (2014). Stochastic Analyses of Electric Vehicle Charging Impacts on Distribution Network. IEEE Transactions on Power Systems, 29(3), 1055-1063. https://doi.org/10.1109/ TPWRS.2013.2291556

National Grid. (2015). Future Energy Scenarios.

National Grid. (2017). Future Energy Scenarios. Retrieved from http://fes. nationalgrid.com/media/1253/final-fes-2017-updated-interactive-pdf44-amended.pdf

Navarro-Espinosa, A., \& Mancarella, P. (2014). Probabilistic modeling and assessment of the impact of electric heat pumps on low voltage distribution networks. Applied Energy, 127, 249-266. https://doi. org/10.1016/J.APENERGY.2014.04.026

Neaimeh, M., Wardle, R., Jenkins, A. M., Yi, J., Hill, G., Lyons, P. F., \& Taylor, P. C. (2015). A probabilistic approach to combining smart meter and electric vehicle charging data to investigate distribution network impacts. Applied Energy, 157, 688-698. https://doi.org/10.1016/J. APENERGY.2015.01.144

Nel, P. J. C., Booysen, M. J., \& van der Merwe, A. B. (2018). A computationally inexpensive energy model for horizontal electrical water heaters with scheduling. IEEE Transactions on Smart Grid, 9(1), 48-56. https://doi. org/10.1109/TSG.2016.2544882

Nissan Motor Corporation, U. (n.d.). Range and Charging: 2017 Nissan Leaf Electric Car. Retrieved May 25, 2018, from https://www.nissan. co.uk/vehicles/new-vehicles/leaf/range-charging.html

Office for Low Emission Vehicles (OLEV). (2018). Reformed Plug-In Car Grant extended into next decade - GOV.UK. Retrieved December 10, 2018, from https://www.gov.uk/government/news/reformed-plug-incar-grant-extended-into-next-decade

Office for National Statistics (ONS). (2017a). Families and Households: 2017. Statistical Bulletin: People, Population and Community. Retrieved from https://www.ons.gov.uk/ peoplepopulationandcommunity/birthsdeathsandmarriages/families/ datasets/familiesandhouseholdsfamiliesandhouseholds

Office for National Statistics (ONS). (2017b). Overview of the UK Population: July 2017. Article: People, Population and Community. Retrieved from http://www.ons.gov.uk/ons/rel/pop-estimate/population-estimatesfor-uk--england-and-wales--scotland-and-northern-ireland/mid-2014/ sty--overview-of-the-uk-population.html

Office of Gas and Electrcity Market (Ofgem). (2017). Ofgem 's proposal to revise the Typical Domestic Consumption Values for gas and electricity, including additional information on the peak and offpeak split for Economy 7 meters, and on the mean consumption for restricted meter customers. Retrieved from https://www.ofgem.gov. uk/system/files/docs/2017/08/tdcvs 2017 open letter.pdf

Office of Gas and Electrcity Market (Ofgem). (2018). Guidance for generators: Co-location of electricity storage facilities with renewable generation supported under the Renewables Obligation or Feed-in Tariff schemes (Version 2). London.

Office of Gas and Electricity Market (Ofgem). (2010). Decision letter: Revision of typical domestic consumption values, 2-4.

Office of Gas and Electricity Market (Ofgem). (2013). Review of typical domestic consumption values, 31.

Office of Gas and Electricity Market (Ofgem). (2015a). Insights paper on households with electric and other non-gas heating, (December), 1-84. Retrieved from https://www.ofgem.gov.uk/ofgempublications/98027/insightspaperonhouseholdswithelectricandothe rnon-gasheating-pdf

Office of Gas and Electricity Market (Ofgem). (2015b). Typical Domestic Consumption Values for gas and electricity 2015, (May), 2-5. Retrieved from https://www.ofgem.gov.uk/gas/retail-market/ monitoring-data-and-statistics/typical-domestic-consumption-values

Parliament of UK. (2018). Automated and Electric Vehicles Act 2018 London: House of Commons. Retrieved from http://www.legislation. gov.uk/ukpga/2018/18/contents/enacted

Protopapadaki, C., \& Saelens, D. (2017). Heat pump and PV impact on residential low-voltage distribution grids as a function of building and district properties. Applied Energy, 192, 268-281. https://doi. org/10.1016/J.APENERGY.2016.11.103 
Shao, S., Pipattanasomporn, M., \& Rahman, S. (2013). Development of physical-based demand response-enabled residential load models. IEEE Transactions on Power Systems, 28(2), 607-614. https://doi. org/10.1109/TPWRS.2012.2208232

UK Energy Research Centre (UKERC). (n.d.). ELECTRICITY USER DEMAND PROFILE DATA. Retrieved May 22, 2018, from http://data.ukedc.rl.ac. uk/simplebrowse/edc/efficiency/residential/LoadProfile/data

UK Met Office. (n.d.). Archive services - Met Office. Retrieved May 12, 2016. from https://www.metoffice.gov.uk/learning/library/archive/services

UK Power Networks. (2014). Impact of Electric Vehicle and Heat Pump Loads on Network Demand Profiles.

United Nations Framework Convention on Climate Change (UNFCCC). Paris Agreement, Conference of the Parties on its twenty-first session §
(2015). https://doi.org/FCCC/CP/2015/L.9/Rev.1

Wärmepumpen-Testzentrum WPZ. (2013). Information sheet of the Heat Pump Test Center WPZ. WPZ - Bulletin. Buchs: University of applied science NTB. Retrieved from https://www.ntb.ch/fileadmin/ NTB_Institute/IES/pdf/Projekte_WPZMPZ_Bulletin_02-2013.pdf

Wemhoener, C. (2011). Final report Annex 32 part 3 Economical heating and cooling systems for low energy houses.

Wemhöner, C., \& Afjei, T. (2003). Seasonal performance calculation for residential heat pumps with combined space heating and hot water production (FHBB method).

Wemhöner, C., Dott, R., Afjei, P. D. T., Huber, H., Helfenfinger, D., Keller, P., \& Furter, P. R. (2007). Calculation method for the seasonal performance of heat pump compact units and validation. 